\title{
LA REGULACIÓN DE LA POLÍTICA MACROECONÓMICA: UN DESAFÍO PARA EL DERECHO PÚBLICO ${ }^{1}$
}

\author{
REGULATING MACROECONOMIC POLICIES: \\ A NEW CHALLENGE TO PUBLIC LAW
}

\author{
Jorge García-Andrade Gómez \\ Profesor Titular de Derecho Administrativo \\ Universidad de Alcalá
}

RESUMEN: El Derecho público se desarrolló bajo un paradigma en el que la intervención del Estado sobre la economía era aún reducida y fundamentalmente se proyectaba de manera individualizada sobre los ciudadanos y empresas, lo que determinó que sus técnicas respondieran a este enfoque. Cuando comenzó a desarrollarse la macroeconomía, a partir de los ańos treinta del siglo pasado, desde el Derecho público no se supo ver la profundidad de la transformación que aquella supuso para el Estado. Por lo que el Derecho público continuó su desarrollo conforme a un enfoque que ya se había visto parcialmente superado, sin adaptarse a la nueva realidad. Sólo recientemente se ha cobrado conciencia de la extraordinaria importancia que tiene la política macroeconómica en el Derecho, por lo que se ha iniciado una regulación tendente a reducir la discrecionalidad de las autoridades económicas. Sin embargo, el resultado se antoja insuficiente para las exigencias de un Estado social y democrático de Derecho contemporáneo y plantea el reto de una renovación en importantes parcelas del Derecho público.

PALABRAS CLAVE: macroeconomía; regulación; discrecionalidad económica; política monetaria; estabilidad presupuestaria; reformas estructurales.

${ }^{1}$ [Fecha de finalización del trabajo: 8 de julio de 2020]. Abreviaturas: AIReF - Autoridad Independiente de Responsabilidad Fiscal; BCE - Banco Central Europeo; BOE - Boletín Oficial del Estado; CE - Constitución Española; IPC - Índice de Precios al Consumo; LJCA - Ley 29/1998, de 13 de julio, Reguladora de la Jurisdicción Contencioso-Administrativa; LOTC - Ley Orgánica 2/1982, de 12 de mayo, del Tribunal de Cuentas; PIB - Producto Interior Bruto; STJUE - Sentencia del Tribunal de Justicia de la Unión Europea; STS - Sentencia del Tribunal Supremo; TFUE - Tratado de Funcionamiento de la Unión Europea; TJUE - Tribunal de Justicia de la Unión Europea; UE - Unión Europea. 
ABSTRACT: Public law was developed under a paradigm where state intervention in the economy was still limited and was conceived to affect citizens and companies on individual basis, which also determined the features of the legal techniques. When macroeconomics surged, in the thirties of the last century, the profound transformation that it meant for the State was not yet noticed. Therefore, public law remained under an approach which had already been partially overcome, without adapting to the new requirements stemming from macroeconomic policies. Only recently the awareness of the extraordinary relevance of macroeconomic policies for law has triggered an incipient regulation in order to fetter macroeconomic discretion. But the outcome is still insufficient to meet the demands of a contemporary social and democratic State under the rule law, and it is requiring a renewal of public law.

KEYWORDS: macroeconomics; regulation; economic discretion; monetary policy; budget stability; structural reforms.

SUMARIO: 1. PLANTEAMIENTO.-2. LA IRRUPCIÓN DE LA POLÍTICA MACROECONÓMICA EN EL DERECHO PÚBLICO.-3. EL DESAJUSTE ENTRE EL DERECHO PÚBLICO Y LA NUEVA REALIDAD MACROECONÓMICA.-4. REGULACIONES PARA REDUCIR LA DISCRECIONALIDAD MACROECONÓMICA: 4.1. La traslación al Derecho de la teoría macroeconómica preponderante: 4.1.1. La transformación de la política monetaria. 4.1.2. La introducción de la estabilidad presupuestaria. 4.1.3. La pretensión de la neutralidad económica. 4.1.4. Las reformas estructurales. 4.2. Técnicas para limitar la discrecionalidad macroeconómica.-5. PRINCIPALES DESAFÍOS PARA EL DERECHO PÚBLICO: 5.1. La reducción del pluralismo democrático. 5.2. El papel del Parlamento: 5.2.1. La incidencia en el equilibrio entre poderes. 5.2.1.1. La posición del Parlamento ante materias muy técnicas. 5.2.1.2. La preterición del Parlamento en relevantes decisiones macroeconómicas. 5.2.2. La incidencia en la protección de los ciudadanos. 5.3. La macroeconomía como contexto para la interpretación jurídica. 5.4. Transparencia y formalización de las decisiones macroeconómicas. 5.5. Participación y control jurisdiccional. 5.6. La reconsideración de la organización institucional: 5.6.1. La problemática de las autoridades independientes. 5.6.2. El solapamiento de las nuevas autoridades. 5.6.3. La necesidad de órganos consultivos y de control macroeconómico.—6. BIBLIOGRAFÍA.

\section{PLANTEAMIENTO}

Desde hace algunas décadas, la economía ha adquirido una importancia dentro del Derecho público que previamente no se había conocido. Lo que no ha pasado inadvertido para la doctrina, que ha producido importantes obras sobre el Derecho público de la economía ${ }^{2}$. No obstante, aquí interesa un concreto ámbito de la economía

2 En los últimos años se han multiplicado las obras generales sobre el Derecho público de la economía, como revelan los siguientes títulos representativos de las aportaciones españolas más recientes: Juan José Carlos LAGUNA DE PAZ, Derecho administrativo económico, Civitas, Madrid, 2019; José MONTERO PASCUAL, Regulación económica, Tirant lo Blanch, Valencia, 2018; Ricardo RIVERO ORTEGA, Derecho administrativo económico, Marcial Pons, Madrid, 2018; Alberto RUIZ OJEDA (dir.), Fundamentos de regulación y competencia: (el diálogo entre derecho y economía para el análisis de las politicas públicas), Iustel, Madrid, 2013; Luis COSCULLUELA MONTANER y Mariano LÓPEZ BENÍTEZ, Derecho público económico, Iustel, Madrid, 2011; Gaspar ARIÑ̃ ORTIZ, Principios de 
que está siendo objeto de una novedosa regulación por el Derecho público, como es la política macroeconómica. Dado que ha sido menos visitada por los juristas, puede ser útil ofrecer una muestra de esta ordenación de contenido macroeconómico:

a) La aprobación del Tratado de Maastricht incluyó la adopción de una moneda única en la UE, que vino acompañada de una detallada regulación macroeconómica sobre los criterios de convergencia para adoptar el actual euro (tipos de interés, déficit, inflación, deuda pública, tipo de cambio); sobre la política monetaria (predeterminando su finalidad e imponiendo importantes restricciones); y estableciendo un sistema institucional muy complejo para administrar la moneda única (con el BCE como autoridad independiente a la cabeza). De manera correlativa, también algunos Derechos nacionales abrieron sus constituciones a la regulación monetaria ${ }^{3}$.

b) También la creciente competencia entre los Estados para atraer inversiones a sus economías ha convertido las llamadas reformas estructurales en términos de uso común, cuyo contenido trata de hacer más competitivos a los países, frecuentemente mejorando sus indicadores macroeconómicos, sirviéndose para ello de reformas en los ordenamientos jurídicos.

c) Desde el final de la Segunda Guerra Mundial, instituciones económicas internacionales, como el Fondo Monetario Internacional, condicionan su apoyo financiero a los países a que estos transformen sus economías, mediante la aplicación de políticas macroeconómicas ${ }^{4}$. A consecuencia de la recesión iniciada en 2007, también las instituciones y países de la UE condicionaron su ayuda a los Estados

Derecho público económico, Comares, Granada, 2004; Luis COSCULLUELA MONTANER (dir.), Estudios de Derecho Público Económico. Libro Homenaje al Prof. Dr. D. Sebastián Martín-Retortillo, Civitas, Madrid 2003. Junto a ellas, son obras tradicionales de referencia en el Derecho español las de Sebastián MARTÍN-RETORTILLO BAQUER, Derecho Administrativo económico, La Ley, Madrid, vol. I, 1988; Ramón MARTÍN MATEO y Francisco SOSA WAGNER, Derecho administrativo económico, Pirámide, Madrid, 1977; y José Antonio MANZANEDO MATEOS et al., Curso de Derecho administrativo económico, Instituto de Estudios de Administración Local, Madrid, 1970. En cuanto a la parte especial, la literatura académica es tan extensa que exime de su cita. Asimismo, acerca de la regulación ante la crisis, véase el número monográfico de Revista Vasca de Administración Pública, 110-II, 2018; Asociación de Letrados del Tribunal Constitucional, Crisis y Constitución, CEPC, 2015; José Luis PIÑAR MAÑAS (coord.), Crisis económica y crisis del Estado de Bienestar. El papel del Derecho administrativo. XIX Congreso Italo Español de Profesores de Derecho Administrativo, Reus, Madrid, 2013; Antonio EMBID IRUJO, La constitucionalización de la crisis económica, Iustel, 2012; Luis COSCULLUELA MONTANER y Luis MEDINA ALCOZ (dirs.), Crisis económica y reforma del régimen local, Civitas, Madrid, 2012; Avelino BLASCO ESTEVE (coord.), El Derecho público de la crisis económica. Transparencia y sector público. Hacia un nuevo Derecho administrativo. Actas del VI Congreso de la Asociación Española de Profesores de Derecho Administrativo, INAP, Madrid 2012.

3 Destaca la reforma de 1992 de la Ley Fundamental de Bonn, que amplió y detalló las previsiones más concisas que ya contenía anteriormente (art. 88); mientras que la reforma de la Constitución Francesa del mismo año añadió el art. 88-2, habilitando la traslación de competencias a la UE en materia económica y monetaria (hoy contenida en una remisión genérica a los Tratados vigentes en el artículo 88-1). En España la Ley 13/1994, de 1 de junio, reguló la autonomía del Banco de España, confiándole plenamente la política monetaria.

${ }^{4}$ Las condiciones impuestas por el FMI pueden leerse en https://www.imf.org/en/About/Factsheets/ IMF-Lending. 
que atravesaban graves dificultades económicas al cumplimiento de severas reformas macroeconómicas 5 .

d) La recesión iniciada en 2007 también ha acabado por generalizar la constitucionalización de la estabilidad presupuestaria en muy distintos Estados de la UE, entre ellos España ${ }^{6}$.

e) Desde 2010, la UE ha reforzado la coordinación de las políticas macroeconómicas de los Estados Miembros, cuya expresión más visible se produce en el denominado semestre europeo, con el que se designa el conjunto de normas y compromisos por los que los Estados Miembros someten al escrutinio de la Comisión y del Consejo sus planes de evolución presupuestaria, programas de reformas estructurales y otras previsiones macroeconómicas.

f) En sede judicial, tanto el Tribunal de Luxemburgo como el Tribunal Constitucional Federal alemán de Alemania han enjuiciado medidas de política monetaria adoptadas por el $\mathrm{BCE}^{7}$.

g) Y en el plano institucional las tradicionales autoridades de fiscalización de las finanzas públicas hoy parecen resultar insuficientes para la nueva situación, por lo que comparten protagonismo, cuando no se ven desplazadas, por otras de nueva planta, como la AIReF o la Autoridad Macroprudencial Consejo de Estabilidad Financiera ${ }^{8}$.

La idea que importa subrayar ahora es que los ejemplos dispersos que acaban de enunciarse en realidad presentan un denominador común, que permite agruparlos y analizarlos de forma conjunta. En su dimensión como fenómeno unitario cabe señalar que desde los años noventa del siglo pasado, en el ámbito de la UE, singularmente en la Eurozona, el Derecho público ha iniciado un proceso de ordenación de las distintas actuaciones públicas de contenido macroeconómico. Algo que no

5 Véase el Memorando de Entendimiento sobre Condiciones de Política Sectorial Financiera, que suscribió España con la UE el 23 de julio de 2012, BOE 10/XII/ 2012. En el momento de concluir estas páginas es previsible que la UE vuelva a imponer a los Estados condiciones macroeconómicas a cambio de su rescate para atender los enormes gastos causados por la pandemia del coronavirus.

${ }^{6}$ Alemania adoptó la estabilidad presupuestaria en su constitución en 2009; España, en 2011; las Conclusiones del Consejo Europeo de los días 24 y 25 de marzo de 2011 aconsejaban que los Estados Miembros elevaran la estabilidad presupuestaria a rango constitucional o norma con fuerza equivalente, al igual que lo dispuso el art. 3.2 del Tratado de Estabilidad, Coordinación y Gobernanza en la Unión Económica y Monetaria; a partir de ese momento, son varios los Estados Miembros que han constitucionalizado la estabilidad presupuestaria, por ejemplo, Francia e Italia en 2012.

7 La STJUE de 16 de junio de 2015, Ganweiler et al., C-62/14, fue dictada a raíz de una cuestión prejudicial planteada por el Tribunal Constitucional Federal alemán, finalmente resuelta en Alemania por la sentencia de 21 de junio de 2016. El caso ha sido ampliamente tratado en los números monográficos Maastricht Journal of European and comparative law, 2016-1; y German Law Journal, 4, 2015. Posteriormente, el TJUE también ha dictado la sentencia de 11 de diciembre de 2018, Weiss et al., C-493/17, si bien, en esta oportunidad, la sentencia de 5 de mayo de 2020 del Tribunal Constitucional federal de Alemania se ha separado del criterio expresado por el TJUE.

${ }^{8}$ Creadas, respectivamente, por la Ley Orgánica 6/2013, de 14 de noviembre, y el Real Decreto 102/2019, de 1 de marzo. 
había sucedido con anterioridad. Lo que se traduce en una importante ampliación en los contenidos del Derecho público, que ahora ha pasado a ocuparse de cuestiones macroeconómicas que, en general, antes le resultaban ajenas o no eran tratadas en todas sus dimensiones. Igualmente resulta novedoso el elevado rango de la normativa reguladora, contenida en tratados internacionales o constituciones, sin perjuicio de su profuso desarrollo en otras disposiciones. Circunstancia que es reveladora de la importancia que aquellas materias han adquirido en la sociedad contemporánea.

Por otra parte, el carácter novedoso de las ordenaciones de decisiones macroeconómicas ha impedido contar hasta el momento con un marco conceptual que permita tomar conciencia de que aquellas ordenaciones forman parte de un fenómeno reciente y con entidad propia, al tiempo que ofrezca las claves explicativas necesarias para abordar su estudio de conjunto. Ante tal carencia, se propone aquí la adopción de un enfoque que no atienda aisladamente a cada una de las manifestaciones del fenómeno (estabilidad presupuestaria, política monetaria, reformas estructurales, etc.), sino que se eleve sobre ellas y las englobe para examinarlas en su conjunto. Solo así será posible entender por qué el Derecho se ocupa ahora de estas cuestiones, cuando en el pasado les prestó menor atención; situar su origen, las ideas que impulsan el fenómeno y las necesidades a que responde; identificar sus manifestaciones; explicar con coherencia las relaciones entre las distintas ordenaciones; así como abordar los retos que plantean al Derecho público. En suma, está pendiente el tratamiento sistemático de la política macroeconómica en el Derecho público, cuya primera aproximación constituye el objeto de este trabajo.

\section{LA IRRUPCIÓN DE LA POLÍTICA MACROECONÓMICA EN EL DERECHO PÚBLICO}

Conviene situar temporalmente el surgimiento de la macroeconomía y ponerla en perspectiva histórica para tratar de entender por qué las políticas macroeconómicas han irrumpido tardíamente como objeto del Derecho público.

Antes del surgimiento de la macroeconomía, la ciencia económica se ocupaba principalmente de la operativa de los individuos, de las empresas, de concretas actividades, industrias o áreas territoriales reducidas, bajo el entendimiento de que la actuación espontánea de los individuos era capaz de corregir por sí misma los desequilibrios económicos que se produjeran. De tal manera que el papel de las autoridades en la economía era más bien reducido y centrado en intervenciones puntuales, así como en actuaciones de carácter social que paliasen las situaciones de necesidad y desprotección. Con ojos actuales, el papel del Estado sobre la economía en su conjunto era de relativa inhibición, en coherencia con la corriente económica predominante, pero también porque la ciencia económica aún no había alcanzado el desarrollo que conocería posteriormente y el Estado carecía de los medios técnicos y humanos para asumir un papel dirigente en el conjunto de la economía. 
Sin embargo, una serie de factores propiciaron el surgimiento de la macroeconomía. Sin que corresponda aquí detenerse en ellos, debe dejarse anotado el desarrollo de la estadística, y muy particularmente de los denominados números índice, merced a las aportaciones de autores como Irving Fisher y William Stanley Jevons, y de la contabilidad nacional, con el protagonismo de Simon Kuznets ${ }^{9}$. Estos desarrollos matemáticos permitieron a los economistas trabajar con indicadores macroeconómicos que ofrecían mediciones aproximadas de realidades muy amplias sin necesidad de contar con todos los datos. Por ejemplo, el IPC mide la evolución de los precios al consumo de un país sin necesidad de integrar en él los precios de todos los millones de transacciones comerciales que cada día se celebran en ese país. Para ello toma y mide únicamente unas muestras representativas de la evolución de los distintos precios, que ofrecen una imagen aproximada de la evolución del nivel general de precios. En el surgimiento de la macroeconomía también deben citarse las lecciones que proporcionó la Primera Guerra Mundial, pues nunca antes los Estados habían movilizado tantos recursos y factores de producción, públicos y privados, al servicio de la conflagración ${ }^{10}$. Lo que a su término legó la enseñanza de que, al igual que los Estados habían podido organizar el conjunto de la economía al servicio de la causa bélica, también podrían dirigirla en tiempos de paz, enderezándola hacia el desarrollo económico y el bienestar de la población. Y, muy principalmente, debe subrayarse la necesidad que impuso la Gran Depresión de 1929, con las terribles secuelas de devastación económica que dejó a su paso, que hizo ver a los economistas y responsables públicos que el mercado no corregía por sí solo sus desequilibrios, como había postulado hasta entonces la doctrina económica mayoritaria. Ante la Gran Depresión, algunos Estados se aventuraron a adoptar medidas auténticamente macroeconómicas, como el New Deal de Roosevelt o las políticas suecas de estímulo, aun sin contar con una teorización que sirviera de guía ${ }^{11}$. En este contexto, el acta de nacimiento de la macroeconomía se sitúa convencionalmente a mediados de los años treinta del siglo $\mathrm{xx}^{12}$, a partir de la publicación en 1936 de la principal obra de John Maynard Keynes, Teoría general del empleo, el interés y el dinero, que recogió la primera gran sistematización teórica de la macroeconomía.

No se quiere expresar que en los siglos previos los poderes públicos no adoptaran importantes medidas para favorecer el desarrollo económico, pues desde finales del siglo $\mathrm{xv}$ los reinos comienzan a ocuparse ampliamente de la economía, unificando mercados, fomentando exportaciones, ya fuera con medidas proteccionistas o

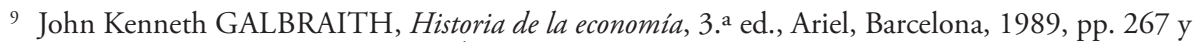
ss.; Robert B. EKELUND y Robert F. HÉBERT, Historia de la teoría económica y de su método, $3 .^{\mathrm{a}}$ ed., McGraw-Hill, Madrid, 1991, pp. 386 y ss.; y Olivier BLANCHARD, Macroeconomía, 7.a ed., Pearson, Madrid, 2017, p. 22.

10 Fritz FLEINER, Instituciones de Derecho Administrativo, Labor, Barcelona, 1933, p. 105; Sebastián MARTÍN-RETORTILLO BAQUER, 1988: 22; Michael STOLLEIS, Origins of the German Welfare State, Marcial Pons, Springer, Berlín, 2013, pp. 89 y ss.; Tony JUDT, Ill fares the land, Penguin, Nueva York, 2010, 55.

11 GALBRAITH, 1989: 229 y ss., 246 y ss.

12 GALBRAITH, 1989: 256 y ss.; y Olivier BLANCHARD, 2017: 495 y ss. 
librecambistas, favoreciendo ciertos sectores: "por primera vez en la Historia europea existe entonces una política de intervención estatal en la economía. Asistimos, pues, a la conversión de la economía en materia de gobierno" ${ }^{13}$, que adquiriría particular relevancia en el siglo xix bajo las ideas de la Ilustración ${ }^{14}$. Sin embargo, la ciencia económica aún no había alcanzado su pleno desarrollo. De manera que aquellas actuaciones de los poderes públicos consistían fundamentalmente en intervenciones directas sobre la esfera individual, como expropiaciones, recargos aduaneros, medidas de fomento y sociales.

Buena prueba de que la irrupción de la macroeconomía constituyó un hito en el desarrollo de las políticas económicas se encuentra en los aspectos organizativos de estas últimas. En el caso estadounidense, antes del desarrollo de la macroeconomía únicamente el Departamento de Agricultura contaba con economistas entre sus técnicos y solo después de la Segunda Guerra Mundial la Administración empezó a incorporar el asesoramiento institucionalizado de economistas ${ }^{15}$. En el caso español, en 1930 se creó un Cuerpo Técnico de Oficiales Comerciales para impulsar el comercio exterior, pero hubo de esperarse a 1956 para la creación del Cuerpo de Economistas del Estado (que acabaría fusionado con el de Técnicos Comerciales), encargados ya del asesoramiento y gestión de las decisiones macroeconómicas ${ }^{16}$. Incluso el proyecto europeo constituye un espejo de la evolución indicada: su diseńo originario respondía más bien al entendimiento previo de la economía (se ocupaba del acero, el carbón y la energía nuclear), mientras que actualmente su centro de gravedad se sitúa en las grandes decisiones macroeconómicas, habiéndose dotado de instituciones al efecto (Ecofin, Eurogrupo, Sistema Europeo de Bancos Centrales).

Por otra parte, debe aclararse que, si bien algunos de los principales instrumentos jurídicos que hoy emplea la macroeconomía, como las figuras del impuesto o del presupuesto público, fueron forjadas históricamente, convendrá reparar en que hasta muy entrado el siglo XX no se conocieron todas las funciones macroeconómicas para las que aquellos instrumentos también podían servir. Esto es, junto a su función primigenia, encerraban una segunda función macroeconómica. Así, el tributo y el presupuesto constituían instrumentos con los que recaudar y gastar recursos públicos, pero aún no se empleaban como instrumentos macroeconómicos pro o contra-cíclicos con los que enfriar o estimular la economía, como se haría posteriormente ${ }^{17}$.

13 Francisco TOMÁS Y VALIENTE, Obras completas. Manual de Historia del Derecho español, vol. II, Centro de Estudios Políticos y Constitucionales, Madrid, 1997, pp. 1071 y ss., 1095, 1231 y ss., 1288 y ss.

${ }_{14} \mathrm{Ibid}$., 1333 y ss. Incluso en el centro y sur de Europa se intentó en 1865 una Unión Monetaria Latina, que acabó fracasando: José Miguel SANTACREU SOLER, "La revolución monetaria española de 1968", Anales de Historia Contemporánea, núm. 10, 1994, pp. 511-523.

15 GALBRAITH, 1989: 277-279.

16 Real Decreto-Ley 681/1930, de 28 de febrero (art. 5) y Ley de 12 de mayo de 1956.

17 Fernando SAINZ DE BUJANDA, "Estado de derecho y Hacienda pública", Revista de Administración Pública, núm. 6, 1951, pp. 193-212 (pp. 199-201), registraba con exactitud cómo a mitad del siglo xx la Economía había empezado a transformar las figuras jurídicas del presupuesto y del tributo, lo que a su juicio exigía un replanteamiento del Derecho financiero: "el Estado intenta canalizar 
La conjunción del desarrollo de la ciencia económica y de una nueva concepción sobre el papel del Estado en la sociedad determinó que las autoridades públicas pasaran a confeccionar modernas políticas macroeconómicas, que ya no atendían únicamente a la problemática de una determinada empresa, rama de actividad o ámbito territorial reducido, sino que buscaban incidir sobre los agregados macroeconómicos del país en su conjunto, movilizando todos los recursos a su alcance: presupuesto, tipos de interés, cantidad de dinero, cotización de la moneda, etc. Conviene aclarar que entre los economistas hoy no existe una línea divisoria clara entre la macro y la microeconomía, pues ambas se consideran parcelas inescindibles en la disciplina económica, sin que sea posible aislarlas en la práctica. Sin embargo, a efectos jurídicos, interesa de manera especial tomar conciencia de que en la actualidad los Estados adoptan una serie de decisiones macroeconómicas que generalmente afectan de manera difusa al conjunto de la economía o a grandes sectores sociales, y ante las cuáles el Derecho público ofrece una pobre respuesta. Lo que contrasta con las medidas de intervención jurídica tradicionales que afectan de manera singularizada a la situación de particulares y empresas, y que han sido el objeto tradicional del Derecho público, por lo que aquí este sí es capaz de ofrecer un prontuario jurídico muy desarrollado ${ }^{18}$.

\section{EL DESAJUSTE ENTRE EL DERECHO PÚBLICO Y LA NUEVA REALIDAD MACROECONÓMICA}

La macroeconomía supuso una auténtica revolución para la ciencia económica y naturalmente para los Estados, que vieron extraordinariamente reforzado su poder de conformación social, pudiendo incidir con sus decisiones macroeconómicas sobre grandes sectores de la población, cuando no de toda en su conjunto, si bien generalmente lo hacían de manera indirecta, a través de decisiones que afectaban a la población de manera difusa.

Desde un punto de vista jurídico, el aspecto que más interesa subrayar aquí es que aquella revolución en la ciencia económica dio lugar a un gran desajuste entre las nuevas políticas macroeconómicas que empezaron a adoptar los Estados y el con-

y dirigir su influencia a través del Presupuesto, transformando el mecanismo financiero en un sistema de producción, de distribución y de consumo de toda la nación [...] lo que tiene importancia decisiva es que el mecanismo financiero, reflejado en el Presupuesto, cumpla con la mayor eficacia la misión que se le encomiende en la economía del país". Ya en nuestros días, la vigente Ley General Tributaria proclama con naturalidad la doble función del tributo en su art. 2, apartado 1: "Los tributos, además de ser medios para obtener los recursos necesarios para el sostenimiento de los gastos públicos, podrán servir como instrumentos de la política económica general y atender a la realización de los principios y fines contenidos en la Constitución".

18 Por ejemplo, el preámbulo de la Ley 38/2003, de 17 de noviembre, General de Subvenciones, diferencia entre la macro y la microeconomía, al tiempo que concibe esta última como una continuación de la primera: "Definido el marco general del equilibrio presupuestario [...], es necesario descender a una esfera microeconómica para trasladar los principios rectores de la Ley de Estabilidad Presupuestaria a los distintos componentes del presupuesto". 
tenido del Derecho público, que en términos generales se siguió desarrollando de espaldas a aquellas.

En efecto, las decisiones de carácter macroeconómico únicamente pueden articularse a través de las instituciones públicas, pues corresponde a las autoridades la adopción de las decisiones políticas, normativas y administrativas correspondientes. Para ello, en sus orígenes la puesta en práctica de las decisiones macroeconómicas se apoyó en un instrumentario público previamente existente, en el que se descubrió la segunda función a que se ha hecho referencia. A pesar de tan profundas transformaciones, lo cierto es que el Derecho público apenas acusó la revolución que supuso la macroeconomía. Razón por la que esta se desarrolló entre disposiciones lacónicas, que a lo sumo se limitaban a reconocer la existencia de decisiones de aquella naturaleza y atribuir la competencia de su adopción a una determinada autoridad. Entre tanto, las técnicas del Derecho público quedaron ancladas en el paradigma previo bajo el que habían sido concebidas, y que consistían tanto en el reconocimiento de prerrogativas administrativas para incidir sobre la esfera jurídica de concretos ciudadanos y empresas (mediante el sistema tributario, la expropiación, las subvenciones, etc.), como en el establecimiento de las garantías correlativas con las que proteger la libertad y el patrimonio de los ciudadanos directamente afectados. No se fue consciente de que con la macroeconomía las autoridades públicas habían adquirido una nueva capacidad con la que afectar de manera difusa a la esfera de los ciudadanos, particularmente a sus derechos e intereses patrimoniales ${ }^{19}$.

El Derecho público en general y el Derecho administrativo en particular deben conciliar dos objetivos en constante tensión, como es facilitar a las autoridades públicas el instrumentario suficiente con el que atender el interés general y, al tiempo, desarrollar un conjunto de garantías formales y sustantivas que protejan los distintos intereses colectivos y particulares frente a la acción de los poderes públicos. Pero la irrupción de la macroeconomía quebró aquellos contrapesos, pues esta nueva forma de actuación de los poderes públicos apenas fue objeto de regulación por el Derecho público. La circunstancia de que las medidas macroeconómicas tuvieran carácter político y difuso determinó que quedaran fuera del sistema de garantías del Derecho administrativo, generalmente concebido para reaccionar frente a la actuación administrativa que incide de manera singularizada sobre concretos ciudadanos. En cambio, el ordenamiento sí proporcionó a las autoridades importantes potestades de actuación macroeconómica. De tal forma que el resultado fue que las nuevas técnicas de intervención macroeconómica otorgaron una extraordinaria discrecionalidad a las autoridades, que durante décadas pudieron actuar en este campo con escasos límites jurídicos.

19 En el Derecho comparado fueron realmente contadas las regulaciones que trataron de embridar estos nuevos poderes del Estado, entre las que pueden citarse las regulaciones de la política monetaria en Estados Unidos y Alemania, José SIMÓES PATRÍCIO, "Autonomía de los bancos centrales: perspectiva de Derecho comparado", Revista de Derecho Bancario y Bursátil, núm. 69, 1998, pp. 9-44 (p. 20); y M. Àngels ORRIOLS SALLÉS y Joan ROCA SAGARRA, El Banco de España y estructura plural: los modelos administrativos de la Reserva Federal americana y del Bundesbank alemán, Marcial Pons, Madrid, 1997. 


\section{REGULACIONES PARA REDUCIR LA DISCRECIONALIDAD MACROECONÓMICA}

\subsection{La traslación al Derecho de la teoría macroeconómica preponderante}

La primera reacción ante el nuevo poder de las autoridades económicas provino del campo de la economía. A la vista de la repercusión que las decisiones macroeconómicas tenían sobre la vida de los ciudadanos, entre los cultivadores de la economía se alzaron voces propugnando la introducción de reglas y límites frente al enorme poder económico que habían reunido las autoridades públicas ${ }^{20}$.

La reacción tardaría en llegar al ámbito jurídico y, de hecho, los ordenamientos jurídicos solo recientemente han comenzado a regular de manera incipiente la adopción de decisiones macroeconómicas. Son varias las causas que han dado lugar a esta nueva regulación: tanto los avances alcanzados en el conocimiento de la economía como la crisis de los años setenta y comienzos de los ochenta cuestionaron la gran discrecionalidad de las autoridades económicas; la mayor integración europea en los años noventa, particularmente con la creación de una moneda única y la interdependencia que ha generado, exigió homogeneizar y disciplinar las políticas económicas de los Estados miembros; y, por último, el reciente fenómeno de la competencia económica entre Estados que, a resultas de la globalización, ha impuesto la introducción de reformas estructurales para hacer la economía de cada país más competitiva, atraer inversiones o mantener el nivel de empleo.

De manera que desde los pasados años noventa se ha iniciado una regulación de la adopción de decisiones macroeconómicas fundamentalmente con el objetivo de reducir la discrecionalidad de las autoridades. Esta normativa traslada al ámbito jurídico los postulados de la teoría económica predominante, que aboga por una mayor ortodoxia en la macroeconomía. En el ámbito de la Eurozona, la traslación de esta ortodoxia macroeconómica al plano jurídico se podría sintetizar en las siguientes ideas, aun a riesgo de incurrir en un excesivo esquematismo: la transformación de la política monetaria; la estabilidad presupuestaria; la pretensión de la neutralidad económica; y las reformas estructurales ${ }^{21}$.

${ }^{20}$ El cuestionamiento de las políticas macroeconómicas se hizo bajo enfoques muy variados. En el ámbito anglosajón su protagonismo se puede personificar en autores como Friedrich von Hayek (austriaco que desarrolló su actividad intelectual en el mundo anglosajón), Milton Friedman, Robert Lucas o James Buchanan; en Alemania se centra en la escuela del ordoliberalismo de Walter Eucken. Las medidas propuestas para limitar la discrecionalidad económica de las autoridades eran asimismo de muy distinto signo, como la vinculación de la política monetaria al crecimiento de la economía, la estabilidad presupuestaria o la autonomía del banco central. Para más detalle, véase infra la nota 36.

${ }_{21}$ Debe aclararse que las regulaciones enunciadas han sido concebidas para situaciones de normalidad económica o de crisis no excesivamente graves. Sin embargo, la concatenación de dos crisis económicas de extraordinaria gravedad, la iniciada en 2007 y la causada por la pandemia en 2020, han obligado a flexibilizar la aplicación de las citadas reglas macroeconómicas. 


\subsubsection{La transformación de la política monetaria}

No se pretende aquí exponer una operación económica y jurídica tan compleja como la transformación de la política monetaria, sino únicamente resaltar que esta constituye el eje principal en torno al que se han articulado otras regulaciones macroeconómicas, así como aportar las claves explicativas imprescindibles para entenderla.

La política monetaria constituye una de las novedades que trajo la irrupción de la macroeconomía, por lo que no estará de más recordar cómo se ha formado ${ }^{22}$. La primera idea que debe retenerse es que la función primigenia de la emisión de moneda fue facilitar a la población un medio de pago, pero también que, junto a ella, los Estados la emplearon para costear sus gastos públicos. La segunda idea relevante es que la emisión de moneda se basaba en la cantidad de metales preciosos con que los Estados contaran, lo que condicionó rígidamente su capacidad de emisión. De suerte que estos generalmente vivían en una situación de constantes estrecheces económicas y de endeudamiento con los banqueros ${ }^{23}$. La situación se alivió un tanto durante el siglo XIX, después de que Inglaterra instaurase el patrón oro, que permitía emitir moneda fiduciaria convertible en oro. El alivio vino porque aquella conversión era solo parcial, de modo que se podía emitir más moneda que las reservas en oro representadas por aquella. El sistema se extendió internacionalmente, en ocasiones tomando la plata como metal precioso. Pero la necesidad de su convertibilidad en metales preciosos, siquiera fuera parcialmente, no dejaba de ser un límite extrínseco para que los Estados pudieran emitir moneda y financiar sus gastos. Lo que llevó, por ejemplo, a España a ser uno de los primeros países a abandonar la convertibilidad de su moneda en $1883^{24}$. En suma, la emisión de la moneda estuvo históricamente sometida a importantes restricciones materiales ${ }^{25}$.

Sin embargo, todo cambió a partir de la Primera Guerra Mundial, pues los enormes gastos públicos que exigió el esfuerzo bélico llevaron a los Estados a abandonar el patrón metálico y a emitir dinero fiduciario, es decir, sin un respaldo en metales preciosos. Esta situación se consideraba absolutamente heterodoxa desde el punto de vista económico, por lo que al término de la guerra los Estados trataron de volver al patrón oro. Sin embargo, nuevamente Keynes consideró una equivocación el intento

22 Pablo MARTÍN-ACEÑA, "The Banco de España, 1782-2017. The history of a central bank”, Estudios de Historia Económica, núm. 73, 2017, pp. 1-80, resume esta evolución a través de la figura del Banco de España.

23 Ramón CARANDE, Carlos Vy sus banqueros, Crítica, Barcelona, 2000.

${ }^{24} \mathrm{El}$ abandono de la convertibilidad no fue declarado formalmente. Desde la Ley Cos Gayón de 1891 España adoptó el sistema de dinero fiduciario, Joan SARDÁ, La política monetaria y las fluctuaciones de la economía española en el siglo XIX, Alta Fulla, Barcelona, 1998, p. 189; Jaume VICENS VIVES, Historia económica de España, Ed. Vicens Vives, 1974, pp. 651-652.

${ }_{25}$ La adopción de la moneda fiduciaria implicó que las autoridades llevasen a cabo políticas cambiarias con respecto a las divisas. No interesa detenerse en esta cuestión, sino simplemente subrayar que aquellas políticas fueron un anticipo de las decisiones macroeconómicas, pero que se volcaban fundamentalmente hacia el exterior, a mantener, reducir o aumentar la cotización de la moneda para favorecer las exportaciones y restringir las importaciones. 
de regresar al patrón oro y abogó por el mantenimiento del dinero fiduciario, esto es, por normalizar una práctica que se había considerado una medida excepcional durante la contienda y la posterior reconstrucción. Asimismo, propuso que las decisiones sobre la administración de la moneda (sobre la cantidad de dinero en circulación o el tipo de interés) se enderezasen a estimular la economía nacional de manera más directa, y no solo a través de la cotización exterior de la moneda ${ }^{26}$.

La extensión internacional de la emisión del dinero fiduciario tras la Segunda Guerra Mundial trajo importantes consecuencias. La primera fue la generalización de la política monetaria como parte de las nuevas políticas macroeconómicas. Generalmente, aquella pasó a ser adoptada por los gobiernos y ejecutada por los bancos centrales, por lo que estos últimos se convirtieron en una pieza fundamental en el engranaje institucional de la macroeconomía, lo que, a su vez, determinó su nacionalización en los numerosos Estados en que aún se mantenían como entidades privadas ${ }^{27}$. La segunda consecuencia es que los Estados podían utilizar la emisión de dinero para financiar sus propios gastos públicos, lo que provocaba inflación y pérdida de competitividad de la economía. Cuando esto último ocurría, los Estados también podían devaluar con relativa discrecionalidad la moneda y de esta manera mejoraban su posición competitiva frente al exterior ${ }^{28}$.

Al plantearse la creación de una moneda única en la UE, se tuvieron muy presentes las anteriores circunstancias y se optó por un modelo que restringiera la discrecionalidad en la utilización de la política monetaria. Lo que en la práctica constituía una enmienda a la totalidad a la utilización de la política monetaria que la mayoría de los Estados había seguido hasta entonces. Para ello, el Tratado de Maastricht acometió una importante ordenación de esta faceta de la macroeconomía, a saber: atribuyó al BCE el monopolio de la emisión de billetes de euro de curso legal (art. 128.1 TFUE); dispuso que su objetivo prioritario sería la estabilidad de precios, sin perjuicio de que pudiera apoyar la política económica, descartando así que la política monetaria pudiera emplearse para otras finalidades (art. 127 TFUE); prohibió que los

26 Robert SKIDELSKY, John Maynard Keynes, RBA, Barcelona, 2013, pp. 465 y ss.

27 En el caso español, el Decreto-ley 18/1962, de 7 de junio, de Nacionalización y Reorganización del Banco de España, expropió las acciones a sus tenedores privados.

28 Merced a las devaluaciones la moneda pasa a tener un menor valor frente a otras divisas, lo que facilita las exportaciones, la atracción de turismo, etc., sin necesidad de imponer especiales sacrificios económicos a la población. De manera que las devaluaciones son un instrumento de política económica que encierra un gran poder redistributivo de los esfuerzos, pero al mismo tiempo, perjudica gravemente a ciertos grupos de la población, como los importadores que ven multiplicado el precio de los productos extranjeros; los inversores internacionales, que ven minorado el valor de sus inversiones; y los ahorradores nacionales, pues el valor de su patrimonio pierde capacidad adquisitiva respecto del exterior. De hecho, los acuerdos de Bretton Woods de 1944 fijaron una convertibilidad de las monedas al dólar y de este al oro, tratando de evitar que los Estados devaluaran artificialmente sus monedas para ganar competitividad, por lo que constituyen una de las primeras regulaciones para reducir la discrecionalidad macroeconómica en el escenario internacional. Véase un resumen de su operativa en Markus K. BRUNNERMEIER et al., The Euro and the Battle of Ideas, Princeton University Press, Princeton, 2016, pp. 79 y ss. 
bancos centrales financiasen a las autoridades públicas (art. 123.1 TFUE); y separó la política monetaria de la política de los Estados, encomendándosela a un Sistema Europeo de Bancos Centrales dotado de fuerte autonomía frente a cualesquiera autoridades (art. 130 TFUE) ${ }^{29}$.

\subsubsection{La introducción de la estabilidad presupuestaria}

La pretensión de eliminar el déficit público y, en consecuencia, la deuda pública que este genera, han sido durante siglos viejas aspiraciones asociadas a la ortodoxia económica, que se remontan al origen mismo de la formación de los parlamentos, precisamente concebidos como mecanismo político de autorización de los tributos y de los gastos. Anhelo político que puede representarse contemporáneamente en el pensamiento del economista James Buchanan, su adalid teórico ${ }^{30}$.

Sin embargo, aquellos postulados ideológicos, por sí solos, no encontraron el consenso suficiente para ser trasladados al plano jurídico. Fue la transformación jurídica de la política monetaria en la UE, que acaba de referirse, la que determinó la constitucionalización de la estabilidad presupuestaria. Efectivamente, la prohibición de que los bancos centrales pudieran financiar a los Estados integrados en la Unión Monetaria colocó a estos últimos en una posición de mayor vulnerabilidad presupuestaria, pues en el futuro ya no podrían financiar con la emisión de moneda el déficit en que incurrieran al excederse en los gastos públicos, sino que habrían buscar aquella financiación endeudándose en los mercados. Así las cosas, el Tratado de Maastricht introdujo el principio de estabilidad presupuestaria, para asegurar la solvencia de los Estados, limitando tanto el déficit público en que podrían incurrir en sus presupuestos, como el volumen de deuda pública acumulada (actualmente, art. 126 TFUE). Exigencia de estabilidad presupuestaria que, como se ha señalado anteriormente, acabó trasladándose a las constituciones nacionales a partir de la recesión de $2007^{31}$.

29 Sobre la actual ordenación monetaria en el Derecho español, véase M. Amparo SALVADOR ARMENDÁRIZ (dir.), Regulación bancaria: transformaciones y Estado de Derecho, Aranzadi, Cizur Menor, 2014; José GARCÍA ALCORTA, El Banco Central Europeo, Civitas, Madrid, 2011; Gabriela PRADO PRADO, La autoridad monetaria en el sistema institucional de la Unión Europea, Tecnos, Madrid, 2006; M. Àngels ORRIOLS I SALLÉS, El Banco Central Europeo y el sistema europeo de bancos centrales. Régimen jurídico de la autoridad monetaria de la Comunidad Europea, Comares, Granada, 2004; Jorge GARCÍA-ANDRADE GÓMEZ, La posición jurídica del Banco de España en el Sistema Europeo de Bancos Centrales, Civitas, Madrid, 2000.

30 James BUCHANAN y Richard E. WAGNER, Democracy in Deficit, Academic Press, Nueva York, 1977.

31 Los estudios jurídicos sobre la estabilidad presupuestaria son extraordinariamente numerosos, sirvan por todos los números monográficos de Crónica Presupuestaria, núm. 1, 2013; Teoría y Realidad Constitucional, núm. 29, 2012; M. Amparo SALVADOR ARMENDÁRIZ, "El principio constitucional de estabilidad presupuestaria y el derecho administrativo", XIV STEM, 2019, pp. 1-49; Josu DE MIGUEL BÁRCENA, "Estabilidad financiera en entornos federales: la nueva Constitución económica del riesgo", Revista de Derecho Constitucional Europeo, núm. 26, julio-diciembre, 2016; M. 


\subsubsection{La pretensión de la neutralidad económica}

Entre las propuestas frente a los efectos indeseados de las políticas macroeconómicas debe incluirse la pretensión de la neutralidad económica. No se trata de un principio económico generalmente aceptado, ni se formula como tal en el ordenamiento jurídico, pero aflora aquí y allá como una reacción frente a la segunda función que la política macroeconómica atribuye a ciertos instrumentos al servicio de las autoridades públicas.

En efecto, una de las características del método macroeconómico consistió en repensar la funcionalidad del instrumentario al alcance del Estado (como el sistema tributario, el presupuesto o la moneda), pues aquellos medios implican una movilización de recursos económicos tan relevante que puede utilizarse para otras finalidades macroeconómicas adicionales a las que justificaron su creación. Frente a este planteamiento, el preconizado principio de neutralidad económica se alza como una forma de reducir el poder de actuación de las autoridades públicas, que deberían limitarse a dar a los instrumentos a su alcance la función primigenia para la que fueron concebidos, de manera que no se desvirtúe su funcionalidad, ni se interfiera en la toma de decisiones de los operadores privados distorsionando el sistema de precios como mecanismo de información.

Como se ha dicho, no es un postulado que goce de general aceptación en el campo de la economía. De hecho, la pujante teoría del análisis económico del Derecho en gran medida propugna un planteamiento contrario, en cuanto que cualquier regu-

Mercè DARNACULLETA I GARDELLA, "Conseqüències institucionals de la limitació del deute públic a les comunitats autònomes i als Länder. Una anàlisi comparada dels mecanismes de control de l'estabilitat pressupostària a Espanya i Alemanya", Revista d'Estudis Autonòmics i Federals núm. 20, 2014, pp. 174-213; Javier GARCÍA ROCA y Miguel Ángel MARTÍNEZ LAGO, Estabilidad presupuestaria y consagración del freno constitucional al endeudamiento, Civitas, Madrid, 2013; Manuel CARRASCO DURAN, "Estabilidad presupuestaria y Comunidades Autónomas", Revista d'Estudis Autonòmics i Federals, 18, 2013, pp. 169-206; David DELGADO RAMOS, "La reciente constitucionalización de la estabilidad presupuestaria: ¿ una reforma necesaria?", Revista de Derecho Politico, 87, 2013, pp. 317-352; Álvaro RODRÍGUEZ BEREIJO, "La reforma constitucional del art. 135 CE y la crisis financiera del Estado", Crónica Presupuestaria, 1, 2013, pp. 5-39; Jorge GARCÍA-ANDRADE GÓMEZ, "La adopción de la estabilidad presupuestaria en la Constitución Española", Ius Publicum Network Review, 2013, núm. 3, pp. 1-69; Martín BASSOLS COMA, "La reforma del articulo 135 de al Constitución espańola y la constitucionalización de la estabilidad presupuestaria: el proceso parlamentario de elaboración de la reforma constitucional", Revista Española de Derecho Administrativo, núm. 2-155, 2012, pp. 21-41; Jorge GARCÍA-ANDRADE GÓMEZ, "La aplicación del principio constitucional de estabilidad presupuestaria a las entidades locales", en Luis COSCULLUELA MONTANER y Luis MEDINA ALCOZ (dirs.), Crisis económica y reforma del régimen local, Civitas, Madrid, 2012, pp. 293-325; y del mismo autor "La reforma del artículo 135 de la Constitución Española", Revista de Administración Pública, núm. 187, 2012, pp. 31-66; Antonio MARTÍ DEL MORAL, "La constitucionalización del principio de estabilidad presupuestaria", en Luis COSCULLUELA MONTANER y Luis MEDINA ALCOZ (dirs.), Crisis económica y reforma del régimen local, Civitas, Madrid, 2012, pp. 271-292; Violeta RUIZ ALMENDRAL, "Estabilidad Presupuestaria y Reforma Constitucional", Revista Española de Derecho Europeo, núm. 41, 2012, pp. 33-112. 
lación jurídica puede servir para tratar de influir en la conducta económica de los individuos ${ }^{32}$.

Donde el principio de neutralidad ha encontrado mayor acogida ha sido en el ámbito tributario ${ }^{33} \mathrm{y}$, por extensión, en las normas ordenadoras de la percepción de ingresos por parte de las Administraciones públicas. De suerte que los precios, tasas públicas y demás recursos que generen ingresos a la Administración deberían limitarse a procurar la cobertura de los costes correspondientes, pero no deberían emplearse para tratar de influir en la conducta de los individuos; como tampoco para la realización de otras políticas públicas, ya sea mediante incentivos que hagan menos onerosa la actividad, o mediante recargos disuasorios que la encarezcan; en el caso de las tasas y precios públicos, únicamente deberían cubrir el coste del servicio, pero no deberían convertirse en una vía de recaudación ${ }^{34}$.

\subsubsection{Las reformas estructurales}

El cuadro regulatorio que acaba de enunciarse restringe de manera muy severa la capacidad de los Estados para allegar recursos económicos. Particularmente limita

32 Gabriel DOMÉNECH PASCUAL, "Por qué y cómo hacer análisis económico del derecho", Revista de Administración Pública, núm. 195, 2014, pp. 99-133 (p. 102). A título de ejemplo, la Ley $39 / 2015$, al regular la evaluación normativa y su adaptación a los principios de buena regulación, dispone que las Administraciones públicas promoverán el análisis económico en la elaboración de las normas (art. 130.2); y la normativa europea aprovecha la enorme movilización de recursos económicos que implica la contratación pública para dotarla de una segunda función económica, consistente en la profundización en el mercado interior, tal y como se reconoce en los documentos de la Comisión Europea sobre el semestre europeo: https://ec.europa.eu/info/business-economy-euroleconomic-and-fiscalpolicy-coordination/eu-economic-governance-monitoring-prevention-correction/european-semester/thematicfactsheets/business-environment_es.

En España ya teníamos experiencia de la utilización de la contratación administrativa para fines distintos de la mera ejecución de la prestación debida. En sentido contrario al impuesto por la UE, la Ley de 14 de febrero de 1907, de Contratación de Productos Nacionales, utilizó con fines proteccionistas la contratación pública, al disponer que, en los contratos por cuenta del Estado para toda clase de servicios y obras públicas, serían admitidos únicamente los artículos de producción nacional.

33 Fritz NEUMARK, Principios de la imposición, Instituto de Estudios Fiscales, Madrid, 1994, p. 284.

${ }^{34}$ Por ejemplo, la Ley 8/1989, de 13 de abril, de Tasas y Precios Públicos, establece bajo la denominación de principio de equivalencia que las tasas tiendan a cubrir el coste del servicio o de la actividad que constituya su hecho imponible (arts. 7 y 19.2), descartando de esta manera que puedan reducirse o incrementarse para la realización de políticas sociales o como recurso para la recaudación, respectivamente. También la Directiva 2009/12/CE del Parlamento Europeo y del Consejo, de 11 de marzo, relativa a las tasas aeroportuarias, busca que su fijación permita cubrir los costes y un beneficio económico, poniendo trabas a que se puedan utilizar a la baja como política de redistribución territorial o al alza con una función recaudatoria (apartado 10 del preámbulo). Sobre esta última regulación, véase Jorge GARCÍA-ANDRADE GÓMEZ, "Regulación de precios aeroportuarios: reserva de ley y liberalización económica", en Regulación y competencia en servicios de interés económico general (SIEG): análisis sectoriales y comparativos, A. RUIZ OJEDA y R. ZAMORA (eds.), Universidad de Málaga, Málaga, 2015, pp. 131-162. 
el recurso a aquellas fuentes de ingresos que exigirían menores sacrificios a la población, al menos en el corto plazo, como son la financiación por el banco central de los gastos públicos y el endeudamiento público. Situación que se ve agravada en un contexto de libertad de movimientos de los capitales que, a su vez, dificulta que los Estados puedan aumentar sensiblemente su recaudación mediante subidas de impuestos. Como se puede entender fácilmente, todo este conjunto de restricciones, condiciona sobremanera el margen de actuación del Estado, con especial incidencia sobre la cláusula de Estado social.

De tal manera que la introducción de las normas limitativas de la discrecionalidad macroeconómica de los Estados los aboca a adoptar otro tipo de medidas macroeconómicas para mejorar su competitividad en el escenario internacional y así atraer inversiones, colocar sus emisiones de deuda pública en mejores condiciones o incrementar las exportaciones ${ }^{35}$. De modo que los Estados se ven impelidos a acometer constantes reformas estructurales en todos los sectores y facetas de sus economías, que conllevan importantes esfuerzos para la población ${ }^{36}$ (reducción del déficit y la deuda pública, mayor exigencia de formación y dedicación laboral, flexibilidad en el empleo, retraso de la edad de jubilación). Es además un proceso sin final, pues los restantes Estados competidores también concurren en la mejora de sus condiciones para hacerse más atractivos económicamente. De aquí que las llamadas reformas estructurales se hayan convertido en el corolario de la regulación de las políticas macroeconómicas.

\subsection{Técnicas para limitar la discrecionalidad macroeconómica}

Como se ha indicado, el objetivo principal de estas regulaciones es limitar el alcance de la discrecionalidad de las autoridades públicas en la adopción de políticas macroeconómicas para evitar los efectos más indeseados de estas últimas ${ }^{37}$. Con tal

35 Sobre la competencia entre Estados o entre ordenamientos jurídicos, véanse Manuel BALLBÉ y Carlos PADRÓS I REIG, Estado competitivo y armonización europea: los modelos norteamericano y europeo de integración, Ariel, Barcelona, 1997, pp. 15 y ss.; y Julio V. GONZÁLEZ GARCÍA, "Globalización económica, Administraciones públicas y Derecho administrativo: presupuestos de una relación", Revista de Administración Pública, núm. 164, 2004, pp. 7-40 (pp. 29-35).

36 Por ejemplo, la Ley 2/2015, de 30 de marzo, de Desindexación de la Economía Española, sustituyó las actualizaciones de precios referidas a la inflación (IPC) por un nuevo índice, que normalmente arroja un resultado inferior, lo que hace más competitiva la economía española, pero también impone a los perceptores de ingresos pérdidas de capacidad adquisitiva respecto de la inflación.

37 La contraposición entre discrecionalidad y reglas en la política macroeconómica es un debate de largo recorrido, cuya iniciación se atribuye convencionalmente a Milton Friedman a final de los años cincuenta cuando abogó por limitar el poder de las autoridades económicas para evitar los efectos perversos de sus políticas y que posteriormente ha tenido una fecunda continuación, por ejemplo, en Finn E. KYDLAND y Edward C. PRESCOTT, "Rules Rather than Discretion: The Inconsistency of Optimal Plans", Journal of Political Economy, vol. 85, 1977, pp. 473-491. A diferencia del liberalismo más anti-estatista y partidario del laissez faire, la reducción de la discrecionalidad en materia macroeconómica parte de un postulado diferente, pues asume que la economía se desenvuelva en un marco fijado por el Estado en el que este cuenta con extraordinarias prerrogativas, pero trata de neutralizarlas sometiéndolas a estrictas reglas jurídicas. Aun cuando el sometimiento de la discrecionalidad económica a reglas 
propósito, la regulación comprende un amplio abanico de técnicas jurídicas de distinta naturaleza que se pueden agrupar como sigue:

a) En primer lugar, destaca la constitucionalización o elevación a tratados internacionales de muchas de las medidas. Dado que las decisiones de contenido macroeconómico frecuentemente se contienen en normas con rango formal de ley, la reducción de la discrecionalidad parlamentaria exige imponer los límites a esta en las normas supremas de cada ordenamiento: en el caso español se ha empleado la Constitución para introducir la estabilidad presupuestaria y en el Derecho de la UE se ha regulado en los Tratados. De esta manera, las limitaciones a la discrecionalidad vinculan desde la más elevada posición en el sistema normativo.

b) También llama la atención la tendencia a apartar determinadas decisiones de contenido macroeconómico de los órganos tradicionales de formulación de la política. La configuración tradicional de los gobiernos como responsables de dirigir la política (artículo $97 \mathrm{CE}$ ), incluida la económica, se alza en un obstáculo para garantizar la anhelada ortodoxia. Por lo que la reducción de la discrecionalidad macroeconómica con frecuencia pasa por diseñar una nueva arquitectura institucional que aparta la adopción de este tipo de decisiones del ámbito gubernamental, confiriéndoselas a autoridades independientes. Incluso cuando el marco general se adopta en sede parlamentaria, la definición y ejecución de la política se atribuyen a autoridades distintas del Gobierno ${ }^{38}$.

c) Otra de las técnicas empleadas consiste en la introducción normativa de severas restricciones sustantivas en el haz de posibles políticas económicas. Restricciones que se concretan en porcentajes, cifras absolutas o indicadores de referencia, entre otros $^{39}$.

d) Estrechamente relacionada con la anterior es la preferencia por los automatismos que excluyen la capacidad de decisión de las autoridades económicas, princi-

no constituya una corriente mayoritaria entre los economistas, se ha incorporado al Derecho de la UE, particularmente de la Eurozona, y desde allí a los ordenamientos nacionales merced al impulso que ha recibido del ordoliberalismo alemán. Una síntesis de este debate puede consultarse en BLANCHARD, 2017: 435 y ss.; BRUNNERMEIER, 2016, pp. 63 y 88 y ss.; Thorsten BECK y Hans-Helmut KOTZ (eds.), Ordoliberalism: A German oddity?, CEPR Press, 2017; y Gabriel MORENO GONZÁLEZ, "La teoría de la Constitución en James Buchanan: hacia un modelo de economía constitucional", Revista de Estudios Politicos, núm. 177, 2017, 1-36. Salvando las distancias, una idea análoga respecto de la política general recoge José ESTEVE PARDO, El pensamiento antiparlamentario y la formación del Derecho público en Europa, Marcial Pons, Madrid, 2019, pp. 9-21, en el sentido de que el advenimiento de las democracias de masas produjo desde final del siglo XIX una reacción entre determinados juristas para tratar de limitar el poder de los parlamentos.

38 El máximo exponente de esta técnica es la regulación de la política monetaria, hoy configurada en sus líneas maestras en los Tratados de la UE, y cuya definición y ejecución se residencia de manera excluyente en un banco central independiente de los gobiernos y de los parlamentos (art. 130 TFUE).

39 Así, el Protocolo número 12 sobre el procedimiento aplicable en caso de déficit excesivo, anejo a los Tratados de la UE, establece un 3 por 100 para el déficit público y un 60 por 100 respecto de la deuda pública (art. 1). Por su parte, la Constitución espańola impone el equilibrio presupuestario a las entidades locales (art. 135.2). 
palmente respecto de medidas que suponen un aumento del gasto en materias muy sensibles a la presión social. Jurídicamente el automatismo se logra mediante la sustitución normativa de los márgenes de decisión por elementos reglados o conceptos jurídicos indeterminados ${ }^{40}$.

e) La reducción de la discrecionalidad en materia económica también se logra mediante la autovinculación de las autoridades económicas a las propias restricciones que adopten estas mismas autoridades ${ }^{41}$. Esta técnica ampliamente empleada en otros ordenamientos, como el alemán y el comunitario ${ }^{42}$, sin embargo, no parece haber sido bien entendida por la jurisprudencia española ${ }^{43}$.

f) La reducción de la discrecionalidad también se articula a través de la introducción de procedimientos complejos para la adopción de decisiones macroeconómicas, jalonados de informes o consultas, requisitos formales y exigencias de mayorías que condicionan el margen de decisión de las autoridades económicas ${ }^{44}$.

40 Sirva como muestra la Ley 23/2013, de 23 de diciembre, Reguladora del Factor de Sostenibilidad y del Índice de Revalorización del Sistema de Pensiones de la Seguridad Social, que definía el factor de sostenibilidad "como un instrumento que con carácter automático permite vincular el importe de las pensiones de jubilación del sistema de la Seguridad Social a la evolución de la esperanza de vida de los pensionistas, a través de la fórmula que se regula en esta norma” (art. 1, hoy derogado).

41 Ejemplo de esta autovinculación es la fijación del objetivo de inflación establecido por el BCE. El art. 127 del TFUE atribuye a la autoridad monetaria el objetivo principal de mantener la estabilidad de precios, sin que la norma incorpore elementos adicionales acerca de qué se entiende por precios estables, cómo se deban medir o fijar estos. Sin embargo, el BCE ha concretado la estabilidad de precios cuantificándola como el incremento interanual del índice armonizado de precios de consumo de la zona del euro en un nivel inferior, aunque próximo, al 2 por 100 a medio plazo (La politica monetaria del $B C E$, BCE, Frankfurt am Main, 2011, p. 9).

42 Mariano BACIGALUPO, La discrecionalidad administrativa, Marcial Pons, Madrid, 1997, pp. 186-187.

43 Véase la STS 236/2015, de 30 de enero de 2005, que considera contrario a Derecho que la Comisión Nacional de los Mercados y de la Competencia calcule el importe de las sanciones siguiendo las pautas publicadas por aquella Comisión en una comunicación sin carácter normativo.

44 Es ilustrativo el procedimiento administrativo y parlamentario que el art. 15 de la Ley Orgánica 2/2012, de 27 de abril, de Estabilidad Presupuestaria y Sostenibilidad Financiera, ha introducido en el ordenamiento para la aprobación de los objetivos de estabilidad presupuestaria y de deuda pública, y que constituye un requisito previo para que el Gobierno pueda elaborar los Presupuestos Generales del Estado:

a) Para la fijación se tendrá en cuenta la regla de gasto recogida en el artículo 12 de la misma Ley y el saldo estructural alcanzado en el ejercicio inmediato anterior.

b) También se tendrán en cuenta las recomendaciones y opiniones emitidas por las instituciones de la UE sobre el Programa de Estabilidad de Espańa o como consecuencia del resto de mecanismos de supervisión europea.

c) La propuesta estará acompañada de un informe en el que se evalúe la situación económica que se prevé para cada uno de los años contemplados. Este informe será elaborado por el Ministerio de Economía y Competitividad, previa consulta al Banco de Espańa, y teniendo en cuenta las previsiones del BCE y de la Comisión Europea.

d) Adicionalmente, se requiere el informe previo del Consejo de Política Fiscal y Financiera de las Comunidades Autónomas, así como de la Comisión Nacional de Administración Local.

e) Se deberá adoptar en el primer semestre de cada año, mediante acuerdo del Consejo de Ministros, que se remitirá a las Cortes Generales. 
g) En fin, para reducir la discrecionalidad macroeconómica también se ha recurrido a un nuevo conjunto de autoridades de evaluación que ejercen novedosos métodos de control sobre las autoridades tradicionales con capacidad de decisión macroeconómica ${ }^{45}$.

\section{PRINCIPALES DESAFÍOS PARA EL DERECHO PÚBLICO}

El Derecho público ha atravesado dos fases respecto de la macroeconomía desde que esta surgió a mediados del siglo pasado. Como ya se ha indicado, en un primer momento el Derecho público no reaccionó suficientemente ante ella. Las escasas regulaciones que se adoptaron se limitaron, en el mejor de los casos, a habilitar el ejercicio de las nuevas potestades, pero el Derecho público no vio adaptadas sus técnicas a aquella nueva realidad que venía a sumarse a la intervención tradicional de las autoridades públicas sobre la esfera patrimonial de los ciudadanos. En una segunda fase iniciada en las últimas décadas, se está abriendo paso una incipiente regulación que, esta vez, ha centrado sus esfuerzos en tratar de limitar la discrecionalidad macroeconómica de las autoridades públicas. Ocurre que el esfuerzo legislativo parece agotarse en el logro de dicho objetivo, sin que se haya planteado abordar toda la problemática que encierra el fenómeno de la integración de la política macroeconómica en el Derecho público. La principal insuficiencia que cabe censurar a la incipiente regulación adoptada en esta segunda fase es que no ha adaptado el sistema de equilibrios entre los poderes públicos, ni ha adecuado el sistema de garantías de los ciudadanos a la nueva realidad.

En nuestro Estado democrático de Derecho, los equilibrios y garantías con que contamos en el campo de la economía fueron concebidos para unas técnicas de corte tradicional, pero junto a ellas hoy existen otras formas de actuación económica más difusas, pero no por ello menos incisivas, que afectan a los restantes poderes públicos y a la esfera patrimonial de los particulares, por lo que también deben ser encauzadas jurídicamente. No basta con una regulación que se limite a reducir la discrecionalidad macroeconómica, sino que falta una mayor ambición que permita adecuar el conjunto del sistema jurídico a las importantes novedades que conlleva aquella regulación, preservando los principios y garantías indisponibles del Estado democrático de Derecho. En este sentido, las páginas que siguen tratan de identificar los

f) En forma sucesiva y tras el correspondiente debate en Pleno, el Congreso de los Diputados y el Senado se pronunciarán aprobando o rechazando los objetivos propuestos por el Gobierno.

g) Si el Congreso de los Diputados o el Senado rechazan los objetivos, el Gobierno, en el plazo máximo de un mes, remitirá un nuevo acuerdo que se someterá al mismo procedimiento.

En su tramitación parlamentaria este procedimiento pone en pie de igualdad al Congreso y al Senado, de tal manera que el rechazo por cualquiera de ellos impediría su aprobación. Sobre la singularidad de esta exigencia, véase Tomás DE LA QUADRA-SALCEDO, "Techo de gasto y separación de poderes", El País, 27 de agosto de 2018.

45 Véase infra el epígrafe 5.6.3. 
principales retos que la regulación de la política macroeconómica plantea al Derecho público, así como apuntan algunas posibles líneas de solución.

\subsection{La reducción del pluralismo democrático}

Uno de los principales desafíos que tiene planteado el Derecho público es la conciliación del principio democrático, más concretamente la preservación del pluralismo, con la reducción de la discrecionalidad en la política macroeconómica. En general, la mayor discrecionalidad macroeconómica acostumbra a corresponderse con unas mayores posibilidades de redistribución inmediata, de políticas más acomodaticias, de mayor extensión de la política social y de mayor igualdad. En cambio, la reducción de la discrecionalidad macroeconómica suele resultar en el contrapunto a la anterior, con una mayor exigencia y competitividad de los individuos y de la sociedad en su conjunto.

En este sentido, las regulaciones sobre la adopción de decisiones macroeconómicas con frecuencia entran en tensión, al menos en el corto plazo, con principios previamente juridificados, generalmente identificados con la cláusula de Estado social y que tienen un valor estructural fruto de una opción del constituyente. Esto ocurre claramente en aquellos ordenamientos como el español, cuyos textos constitucionales se elaboraron bajo un paradigma en el que no se contemplaba la reducción de la discrecionalidad macroeconómica. Lo contrario ocurre en el Derecho de la UE, cuyos Tratados reflejan de manera elocuente esta última tendencia. Y, como quiera que las regulaciones de la discrecionalidad macroeconómica reducen la capacidad de decisión política en este campo, también contraen el pluralismo democrático, concretamente limitan el desarrollo de las políticas identificadas con una mayor redistribución en el corto plazo.

En el plano jurídico se antoja muy difícil la conciliación de dos ideas tan antitéticas, la voluntad de reducir la discrecionalidad macroeconómica de las autoridades y la necesidad contar con tal discrecionalidad para que puedan desplegarse las distintas opciones políticas y con ellas el pluralismo. Además, en este debate no se ventilan únicamente posiciones ideológicas sobre la eficiencia económica y la redistribución en la sociedad, sino que se ve alimentado por la desconfianza y la interdependencia entre Estados a que ha dado lugar la creación de la moneda única en la UE.

\subsection{El papel del Parlamento}

Las carencias de las actuales regulaciones son muy elocuentes al analizar el papel del Parlamento, pues en esta materia ha perdido gran parte de su protagonismo en la adopción de las decisiones más relevantes que afectan a la comunidad, fundamentalmente en dos planos: el del necesario equilibrio entre poderes y el de la protección de los ciudadanos. 


\subsubsection{La incidencia en el equilibrio entre poderes}

\subsubsection{La posición del Parlamento ante materias muy técnicas}

Convendrá empezar por aclarar que el Parlamento conserva su poder de intervención en el diseño de gran parte de las políticas económicas, en la medida en que aprueba los objetivos de estabilidad presupuestaria, los Presupuestos Generales del Estado, así como las reformas constitucionales, la ratificación de los Tratados, y la adopción de las leyes en las que se contienen los elementos nucleares de las regulaciones de contenido macroeconómico.

Sin embargo, la adopción de algunas decisiones macroeconómicas exige calibrar y tener presentes no solo las consecuencias inmediatas, sino también sus efectos futuros y de conjunto para la economía, ya que muchas de las medidas pueden determinar la futura capacidad de decisión de las autoridades, así como las condiciones económicas en que se desarrollará la vida social. Pero tal ejercicio de anticipación dista mucho de ser sencillo y accesible para los legos, por lo que la intervención parlamentaria en materias macroeconómicas no asegura por sí sola la adecuada ponderación y asunción de sus consecuencias. Ciertamente, esto mismo puede acontecer en otras facetas de la vida social, pero una de las singularidades de la regulación que nos ocupa es que se contiene en normas de muy elevado rango (constituciones, tratados), difícilmente modificables, por lo que congelan su proyección sobre el conjunto del ordenamiento. En estas circunstancias, la posición del Parlamento es muy asimétrica respecto del Ejecutivo, pues en la adopción de sus decisiones este último cuenta con unos datos, análisis, informes y asesoramiento altamente especializado, de los que carecen las Cámaras.

Como ejemplo de la falta de conocimiento sobre el alcance de las medidas que se adoptan puede servir la creación de una moneda única en la UE, en cuya virtud los Estados se desapoderaron de una de sus más importantes prerrogativas económicas. A pesar de la trascendencia de la medida, la explicación de esta iniciativa solo atendió a sus efectos más visibles y no a las consecuencias futuras ${ }^{46}$. Aunque estas han acabado aflorando con el estallido de las crisis económicas de 2007 y 2020, cuando se ha puesto de relieve que el Estado ya no disponía de algunos de los más importantes mecanismos de reacción frente a las crisis ${ }^{47}$, y también que la moneda única exigía

46 Es conocido que el Gobierno únicamente consultó al Tribunal Constitucional sobre la compatibilidad entre el Tratado de la UE y la Constitución en relación con el derecho de sufragio en las elecciones municipales (Declaración 1/1992 de 1 de julio).

47 Como ha expresado Klaus TUORI, "el escenario económico de la Eurozona se parecería más a un patrón oro mejorado que a un ámbito en el que se desarrollen políticas monetarias activas. En todo caso, es más que cuestionable que todos los Estados miembros sean conscientes de ello o que lo apoyen, aun siendo éste el modelo que claramente quedó plasmado en el Tratado de Maastricht", "¿Órgano experto, institución política o parte interesada? Roles del banco central europeo en la actual crisis económica”, El Cronista del Estado social y democrático de Derecho, núm. 39, 2013, pp. 50-61 (p. 58). 
una estabilidad presupuestaria que ha transformando el entendimiento de la cláusula de Estado social y autonómico.

\subsubsection{La preterición del Parlamento en relevantes decisiones macroeconómicas}

La posición del Parlamento evidencia la falta de una reconsideración general del papel de las instituciones del Estado respecto de la adopción de las decisiones macroeconómicas. En estas cuestiones la Constitución española resulta en exceso formalista y, dado que algunas de las más importantes decisiones macroeconómicas no requieren la adopción de leyes, frecuentemente se sortea la intervención del Parlamento.

Véase en este sentido la asimétrica regulación de los planes de reforma en el llamado semestre europeo en el Derecho de la UE y el español. En su virtud, los Estados deben aprobar anualmente los programas de las reformas estructurales que introducirán a medio plazo en sus ordenamientos. El Derecho de la UE otorga gran importancia a la planificación macroeconómica de los Estados, tanta que el Reglamento 1466/97 del Consejo establece una supervisión multilateral de aquellos programas, consistente en obligar a los Estados a que sometan los programas de reforma al examen de la Comisión y del Consejo, que se pronunciarán sobre su coherencia y adecuación. Sin embargo, en el Derecho español los planes de reforma son aprobados por el Gobierno, sin intervención del Parlamento, que solo es informado una vez elaborados. Nuevamente se pone de relieve una asimetría difícilmente justificable: si la planificación de las reformas estructurales es tan relevante que exige el escrutinio de la Comisión y del Consejo, no se entiende que el Parlamento nacional sea preterido en su adopción.

\subsubsection{La incidencia en la protección de los ciudadanos}

La participación del Parlamento como garantía de los ciudadanos frente a la intervención del poder público se resiente igualmente cuando la adopción de decisiones macroeconómicas no requiere la tramitación de una norma con rango formal de ley. Como es sabido, el principio de reserva de ley se justifica en la conveniencia de asegurar el debate plural, la transparencia y la representación democrática en la adopción de las decisiones más relevantes para la comunidad, ya afecten a la organización institucional básica del Estado, ya a las finanzas públicas, o a la esfera de derechos y libertades de los ciudadanos. Sin embargo, tal principio no se aplica con igual intensidad cuando las decisiones macroeconómicas revisten carácter difuso, por muy incisivas que sean para la esfera patrimonial de los ciudadanos.

Dos ejemplos recientes y concatenados pueden ayudar a dimensionar la relevancia para la ciudadanía de algunas de estas decisiones macroeconómicas y evidenciar la preterición del Parlamento. Al comienzo de la crisis económica de 2007, cuando las autoridades constataron que gran parte del sistema bancario requería una profunda reestructuración se plantearon esencialmente dos alternativas: la primera de ellas pasaba por un rescate generalizado con fondos públicos; la segunda, por permitir que 
las entidades siguieran operando, a pesar de su endeble situación, de manera que con el tiempo ellas mismas fueran generando el capital suficiente para sanearse ${ }^{48}$. Ambas decisiones llevaban asociados efectos macroeconómicos de extraordinaria importancia: el rescate con fondos públicos habría exigido un endeudamiento público muy elevado; mientras que la segunda medida preservaba en mayor medida las finanzas públicas, pero agravaría severamente la crisis, pues determinaría la paralización de buena parte de la actividad económica, dado que la banca reduciría drásticamente su financiación al sector productivo, con el resultado de que se produciría el cierre de decenas de miles de empresas y la pérdida de millones de puestos de trabajo. Finalmente, las autoridades económicas espańolas optaron por la segunda medida y el Congreso aprobó una proposición no de ley que fijaba las bases y principios de la restructuración bancaria con el criterio de que costase lo menos posible ${ }^{49}$, sin embargo, esta toma de posición se adoptó sin que se informase o se debatiesen la disyuntiva ni las consecuencias de cada opción ni las posibles alternativas.

La decisión se reveló a la postre desacertada, por lo que también hubo de acudirse a la primera de las opciones, el rescate generalizado de las cajas de ahorro. Si bien a esas alturas de la crisis fue preciso que, a su vez, el Estado también fuera rescatado por la UE, para lo que suscribió un fuerte empréstito, condicionado a la aplicación de un programa de profundas reformas macroeconómicas ${ }^{50}$. El contenido de este conjunto de medidas es extraordinariamente complejo, pero en lo que aquí interesa deben destacarse varios aspectos. El primero es que, dado que la adopción del euro supuso que el Estado perdiera su capacidad de devaluar la moneda para recuperar la competitividad, el Memorando estableció una planificación macroeconómica para llevar a cabo una devaluación interna, esto es, una rebaja de salarios, precios y costes en la sociedad mediante reformas legislativas de distinto orden. El segundo, es que esta planificación se adoptó al margen del Parlamento y su materialización se publicó como meros acuerdos por la Secretaría General Técnica del Ministerio de Asuntos Exteriores y Cooperación. Ciertamente, las concretas reformas legislativas exigidas por el Memorando hubieron de ser posteriormente adoptadas en sede parlamentaria, no así la planificación macroeconómica de conjunto, como tampoco el consenti-

48 La disyuntiva se expone aquí en términos muy esquemáticos, pues la segunda de las decisiones fue acompañada de importantes medidas de apoyo a la banca, como un conjunto de fusiones y absorciones, la intervención singular de algunas entidades de crédito y el otorgamiento de importantes avales del Estado en favor de la banca: Real Decreto-ley 7/2008, de 13 de octubre, de Medidas Urgentes en Materia Económico-Financiera en relación con el Plan de Acción Concertada de los Países de la Zona Euro; Real Decreto-ley 4/2009, de 29 de marzo, por el que se Autoriza la Concesión de Garantías Derivadas de la Financiación que pueda Otorgar el Banco de Espańa a Favor de Caja de Ahorros de Castilla-La Mancha; y Real Decreto-ley 9/2009, de 26 de junio, sobre Reestructuración Bancaria y Reforzamiento de los Recursos Propios de las Entidades de Crédito.

49 José Luis RODRÍGUEZ ZAPATERO, El dilema, Planeta, Barcelona, 2013, p. 197.

50 Acuerdos de Facilidad de Asistencia Financiera y de Trasferencia y Asunción (BOE 10/XII/2012) y Memorando de Entendimiento sobre condiciones de Política Sectorial Financiera, y Acuerdo Marco de Asistencia Financiera (BOE 10/XII/2012). 
miento a ella, el debate sobre su oportunidad, sus objetivos, instrumentos, alternativas y fórmulas de mitigación o redistribución de los sacrificios ${ }^{51}$.

Creo que estos ejemplos muestran con claridad la inadecuación del Derecho público actual para disciplinar el ejercicio del poder en materia macroeconómica, pues ni la Constitución, ni la jurisprudencia constitucional, ni las leyes exigen el consentimiento parlamentario para adoptar decisiones macroeconómicas tan trascendentales para el Estado y la sociedad. Esta falta de atención del Derecho público hacia las medidas macroeconómicas de efecto difuso contrasta vivamente con las rigurosas garantías exigidas en nuestro ordenamiento jurídico respecto de aquella intervención económica tradicional que incide de manera individualizada en la esfera patrimonial de los ciudadanos. Es muy paradójico que la protección patrimonial de los individuos haya llevado al Tribunal Constitucional a exigir la intervención parlamentaria para la aprobación de una tasa portuaria (STC 101/2009) y, sin embargo, decisiones que implican el cierre de decenas de miles de empresas, la pérdida de millones de trabajos o la devaluación general de la economía se adopten al margen del Parlamento.

De los anteriores epígrafes cabe concluir en la necesidad de que el Parlamento cuente con asesoramiento experto para poder valorar la trascendencia de las decisiones macroeconómicas que se someten a su intervención, así como de las que se adoptan extramuros. Y, respecto de estas últimas, también procede considerar fórmulas que aseguren el consentimiento de las Cámaras (mediante ley o autorización), a lo que contribuiría el reconocimiento a las minorías parlamentarias de la capacidad de someter al Parlamento la consideración, debidamente documentada, de las decisiones macroeconómicas.

\subsection{La macroeconomía como contexto para la interpretación jurídica}

Las decisiones macroeconómicas generalmente se formulan en un plano muy abstracto y general, así como tienen un alcance difuso, por lo que muchas veces su puesta en práctica requiere el desarrollo posterior de medidas legislativas y administrativas concretas en las que ya es posible identificar los concretos grupos o individuos que se verán afectados por ellas.

Esta dualidad de planos da lugar a desajustes adicionales en el Derecho público, pues la aplicación de las medidas de desarrollo y la resolución de las controversias jurídicas a que dan lugar se desconectan con frecuencia del marco general en que se adoptaron, sin conciencia de que este debería guiar su interpretación. Esta forma descontextualizada de aplicar el Derecho impide ponderar todos los factores que

51 Se deja al margen del análisis si tales compromisos constituyeron tratados internacionales a los efectos de la formación interna de la voluntad del art. $94 \mathrm{CE}$, pues desde el punto de vista de la prestación externa del consentimiento sí parecen reunir los requisitos poco formalistas del art. $11 \mathrm{del}$ Convenio de Viena sobre el Derecho de los Tratados. 
exigirían tanto la ejecución como el juicio de validez sobre las medidas ${ }^{52}$ : si es proporcionada para la finalidad propuesta, si respeta el principio de igualdad, o si toda la población o el conjunto de sectores y grupos sociales están soportando sacrificios equivalentes. En suma, muchas de las medidas técnicas de desarrollo y de aplicación se legitiman en el marco más amplio que las orienta, por lo que, sin esta perspectiva, pueden perder su justificación.

Un ejemplo tomado de la pasada recesión económica ilustra sobre los resultados diametralmente opuestos a que puede dar lugar el enjuiciamiento de una medida de ejecución, según que se contextualice o no en su marco macroeconómico. La grave situación de las cuentas públicas obligó a las autoridades a reducir drásticamente el déficit público y para su efectiva ejecución se acordaron distintas medidas concretadas en la reducción de las retribuciones de los empleados públicos, las subvenciones, los incentivos fiscales, las inversiones públicas y otras, de las que ahora interesa la reducción de la retribución a las energías renovables ${ }^{53}$. Cuestionada la validez jurídica de estos recortes por considerarlos contrarios a la seguridad jurídica y la confianza legítima, el Tribunal Constitucional respaldó la validez de la medida otorgando gran peso a su contexto macroeconómico: se adoptaba en un marco general de restricciones presupuestarias [STC 270/2015, FJ 7.a)]; mientras que numerosos arbitrajes internacionales han considerado contrarios a Derecho los recortes ${ }^{54}$, atendiendo principalmente a la naturaleza de los compromisos asumidos entre el inversor individual y el Estado, con abstracción de la afectación a los restantes operadores en la economía 55 .

La importancia de la contextualización de las medidas en su marco general es reconocida en otras parcelas del Derecho público, como ocurre en materia de planificación ambiental, hasta el punto de que los planes y programas de carácter estratégico son evaluados separadamente por los efectos que tendrán luego sobre los concretos proyectos de ejecución, que también se evalúan (Ley 21/2013, de 9 de diciembre, de Evaluación Ambiental). La contextualización también es objeto de estudio atento

52 Una posición distinta a la aquí defendida puede encontrarse en Paloma REQUEJO RODRÍGUEZ, "El papel de la crisis económica en la argumentación del Tribunal Constitucional. Comentario a la STC 19/2014”, Teoría y Realidad Constitucional, núm. 36, 2015, pp. 417-437 (p. 430).

53 Real Decreto-ley 9/2013, de 12 de julio, por el que se Adoptan Medidas Urgentes para Garantizar la Estabilidad Financiera del Sistema Eléctrico.

54 Los laudos del Centro Internacional de Arreglo de Diferencias Relativas a Inversiones también reconocen la capacidad del Estado de modificar su ordenamiento jurídico, pero tienden a primar las "expectativas legítimas y razonables" del concreto inversor: esta tendencia general se ejemplifica en el laudo Eiser ARB/13/36; mientras que solo excepcionalmente se reconoce la licitud de los recortes, por ejemplo, en el reciente laudo Stadtwerke, ARB/15/1.

55 No se oculta que el canon de enjuiciamiento difería en ambas instancias, el Tribunal Constitucional y el Centro Internacional de Arreglo de Diferencias Relativas a Inversiones, pues en un caso la referencia normativa era la $\mathrm{CE}$ y en el otro, unos tratados internacionales de protección de inversores. Sin embargo, también debe tenerse presente que no se enjuiciaba un incumplimiento textual de una disposición, sino la justificación de una medida a la luz de parámetros tan genéricos como su previsibilidad, la seguridad jurídica y las "expectativas legítimas y razonables" del inversor, por lo que creo que los términos de la comparación resultan oportunos. 
en la reforma del Derecho administrativo iniciada en Alemania, bajo la denominada teoría de la dirección, que, entre otros aspectos, realza la importancia de los distintos instrumentos de dirección de las conductas sociales, que ya no son exclusiva ni preponderantemente las leyes ${ }^{56}$.

\subsection{Transparencia y formalización de las decisiones macroeconómicas}

La contextualización de las distintas decisiones jurídicas exige el adecuado conocimiento y comprensión por parte de los operadores jurídicos del marco macroeconómico general en que aquellas se dictan. Ahora bien, los operadores frecuentemente serán profanos en economía, de manera que también será preciso atender a las exigencias de transparencia y formalización propias de un Estado de Derecho avanzado.

La transparencia constituye una exigencia para que la ciudadanía esté informada y el conjunto de los poderes públicos pueda ejercer adecuadamente sus funciones de codecisión o control. Como dispone la Ley de Transparencia, la información deberá proporcionarse de oficio, actualizada, periódica y "de una manera clara, estructurada y entendible para los interesados" (art. 5), así como acompańada de las proyecciones, cálculos, estudios de alternativas e informes relevantes. Exigencia que dista mucho de la situación actual, en la que, como se ha expuesto en anteriores ejemplos, no se han hecho públicos algunos de los debates sobre las más relevantes decisiones macroeconómicas que han afectado al Estado y la sociedad. En este sentido, es dudoso que las previsiones de la actual Ley de Transparencia basten para traer la suficiente luz al campo de la macroeconomía, dado que muchos de los debates e incluso de las decisiones en esta materia no se documentan, por lo que puede ser necesario imponer determinadas obligaciones sectoriales de publicidad activa.

En cuanto a la formalización de la política macroeconómica, se hace preciso encauzar y formalizar la adopción de las decisiones macroeconómicas más relevantes adecuándolas al ordenamiento jurídico en que se insertan. Esta exigencia supone que tales decisiones se adopten, publiquen y comuniquen en instrumentos jurídicos formales; y que estén motivadas, para así garantizar la certeza, su conocimiento íntegro $y$, en su caso, la posibilidad de impugnarlas ${ }^{57}$.

La regulación del BCE puede servir para entender aquella problemática. El TFUE se muestra innovador al limitar la discrecionalidad en la política monetaria, confiándosela a un banco central independiente como ya nos consta. Pero, paradójicamente, el Tratado se sirve de las técnicas tradicionales del Derecho público para ordenar esta nueva realidad, a pesar de que aquellas fueron concebidas para proteger a particulares

56 Eberhard SCHMIDT-ASSMANN, "Cuestiones fundamentales sobre la reforma de la teoría general del Derecho administrativo", en Javier BARNES (ed.), Innovación y reforma en el Derecho administrativo, 2. a ed., Global Law Press, Sevilla, pp. 21-140 (p. 47).

${ }^{57}$ La falta de formalización jurídica de la economía ya fue denunciada por Sebastián MARTÍNRETORTILLO BAQUER, "Las nuevas perspectivas de la Administración económica", Revista de Administración Pública, núm. 116, 1988, pp. 31-47 (pp. 44-45). 
singularmente afectados por intervenciones públicas en su esfera patrimonial, sin haberlas adaptado al nuevo poder macroeconómico de alcance difuso que ha establecido. Así, respecto de cuestiones un tanto accesorias el TFUE sigue el esquema tradicional de reserva de ley para la imposición de obligaciones y la regulación del régimen sancionador, de manera que el BCE no podrá actuar autónomamente en esta materia, sino que la competencia corresponde al Consejo de la UE a través de reglamentos (art. 41 del Protocolo núm. 4). En cambio, algunas de las decisiones más relevantes sobre la política monetaria se residencian en el BCE, que las da a conocer mediante notas de prensa o referencias en publicaciones periódicas de carácter informal, como es la propia definición de la estabilidad de precios, que constituye su objetivo primordial ${ }^{58}$. Las notas de prensa se han empleado incluso para comunicar la decisión más trascendente que jamás haya adoptado el BCE, como fue la transformación de su política monetaria para rescatar la economía de la Eurozona, que esta institución decidió los días 5 y 6 de septiembre de 2012. Precisamente fue objeto de discusión ante el TJUE la circunstancia de que una medida tan trascendente y heterodoxa hubiera sido comunicada en una nota de prensa y es interesante constatar que los relevantes efectos económicos de la decisión llevaron al Abogado General a proponer la admisión de su enjuiciamiento: "la capacidad de influir decisivamente en la situación jurídica de terceros justifica que su tratamiento como «acto» se aborde con un enfoque antiformalista" 59 .

\subsection{Participación y control jurisdiccional}

La regulación del medio ambiente guarda notables paralelismos con la ordenación de la política macroeconómica, aunque la primera ha alcanzado un grado de desarrollo jurídico muy superior, por lo que puede servir de guía a la segunda. Por ejemplo, el Derecho ambiental ha adaptado los instrumentos tradicionales de control jurídico respecto de aquellas actuaciones públicas que, aun teniendo efectos difusos, son extraordinariamente relevantes para la salud de los ciudadanos y el medio ambiente. Como es conocido, en el Derecho ambiental este control se asienta sobre la transparencia informativa y otros dos elementos que se consideran indisociables, la participación social y el control jurisdiccional, este último articulado mediante un sistema de acción popular y de ampliación en el reconocimiento de la legitimación activa (Ley 27/2006, de 18 de julio).

La transparencia, la participación y el control de las actuaciones públicas de efectos difusos son actualmente técnicas irrenunciables para lograr una realización eleva-

58 Monthly Bulletin, ECB, January, 1999, p. 46; Monthly Bulletin, ECB, June, 2003, p. 5; y La politica monetaria del BCE, BCE, Frankfurt am Main, 2011, p. 9. Sobre la relevancia jurídica de esta cuestión, véase Jorge GARCÍA-ANDRADE GÓMEZ, "El sistema monetario en una Unión Europea de Derecho", en M. Amparo SALVADOR ARMENDÁRIZ (dir.), Regulación bancaria: transformaciones y Estado de Derecho, Aranzadi, Cizur-Menor, 2014, pp. 251-320 (pp. 298 y ss.).

59 Conclusiones de 14 de enero de 2015, C62/14, Gauweiler et al., apartado 76. 
da y exigente de la cláusula de Estado democrático de Derecho, en cuanto refuerzan la legitimación en el ejercicio del poder y son prendas de acierto en la adopción de las decisiones que afectan a la colectividad, al enriquecer la información disponible, la pluralidad de puntos de vista e imponer un escrutinio sobre la actuación pública. En igual sentido, la juridificación de la política macroeconómica exige reparar las deficiencias en el sistema de transparencia, así como rectificar el papel residual y pasivo que nuestro Derecho asigna actualmente a la sociedad en la formulación de las distintas políticas macroeconómicas, potenciando la participación social, mediante cauces efectivos de iniciativa, así como de formación y expresión de la opinión pública.

Igualmente es necesario reconsiderar el régimen de la legitimación procesal activa para permitir el control efectivo por parte de los ciudadanos y las organizaciones en que se agrupan de aquellas decisiones macroeconómicas que afectan a su esfera patrimonial, aunque tengan carácter difuso. La tensión entre las demandas sociales de protección frente a estas actuaciones y el insuficiente reconocimiento de la legitimación activa para hacerla efectiva ante los tribunales se ha puesto de manifiesto en la impugnación de las medidas heterodoxas de política monetaria acordadas por el BCE, recurridas por decenas de miles de ciudadanos alemanes, a quienes el TJUE inicialmente no reconoció legitimación ${ }^{60}$, mientras que el Tribunal Constitucional Federal alemán sí se la otorgó y acabó presentando varias cuestiones prejudiciales ante el TJUE ${ }^{61}$.

No se propugna aquí una alteración del sistema de impugnación de las decisiones políticas, pues muchas de ellas se contienen en normas con rango formal de ley y no se pretende el reconocimiento de una legitimación popular ante el Tribunal Constitucional frente a aquel tipo normativo. Como tampoco se defiende que los tribunales puedan sustituir la discrecionalidad que aún se reconoce a las autoridades públicas en la adopción de las políticas macroeconómicas. Más sencillamente se trata de adecuar el actual sistema de impugnaciones a la importancia que la macroeconomía ha adquirido para la colectividad. Si la regulación ha reducido la discrecionalidad macroeconómica de las autoridades mediante la introducción de requisitos, límites, elementos reglados, nuevos principios y procedimientos, los ciudadanos, e incluso las fuerzas políticas, deberían poder plantear ante la jurisdicción ordinaria su revisión, sin que se alce en un impedimento la actual exigencia de que las medidas les afecten de manera singularizada (art. 19 LJCA) ${ }^{62}$.

60 Auto de 14 de noviembre de 2016, T-492/12, von Storch et al.

${ }^{61}$ Resueltas en las sentencias de 16 de junio de 2015, Gauweiler et al., C-62/14, y de 11 de diciembre de 2018, Weiss et al., C-493/17. La posterior sentencia del Tribunal Constitucional Federal de Alemania de 5 de mayo de 2020, en el caso Weiss, precisamente enfatiza la importante incidencia de las medidas macroeconómicas sobre la población: la política monetaria del BCE tiene un impacto en la práctica totalidad de los ciudadanos, quienes se ven afectados, al menos de manera indirecta, en su condición de accionistas, inquilinos, propietarios inmobiliarios, ahorradores o tomadores de seguros (párrafo 173).

${ }^{62}$ La STS 1093/2014, de 3 de marzo de 2014, desestimó la impugnación presentada por un partido político parlamentario contra el reglamento que regulaba la denominada amnistía fiscal, por considerar que tal medida no afectaba a sus derechos o intereses legítimos. No se entiende que no se reconozca 


\subsection{La reconsideración de la organización institucional}

Las nuevas regulaciones en materia macroeconómica conllevan una notable alteración de la organización institucional, fundamentalmente porque implican la creación de nuevas autoridades independientes o la transformación de las existentes, en unos casos para encomendarles la adopción de decisiones macroeconómicas que antes correspondían a los gobiernos, en otros, para que asuman nuevos cometidos, básicamente de control de la discrecionalidad macroeconómica de otras autoridades. Esta regulación institucional plantea esencialmente tres tipos retos para el Derecho público: el primero de ellos es el encaje de las autoridades independientes en el sistema constitucional; el segundo es el acomodo de algunas de las nuevas autoridades respecto de las tradicionales; el tercero se refiere a la necesidad de que el sistema cuente con órganos especializados de asesoramiento y control macroeconómico.

\subsubsection{La problemática de las autoridades independientes}

La generalización de autoridades independientes plantea un problema constitucional que, no por conocido, es menos arduo de resolver. Además, no es exclusivo de la macroeconomía, sino que afecta a otras parcelas de la economía y el Derecho, como la seguridad nuclear. En todo caso, se presenta de manera más acusada en la política monetaria, por lo que los bancos centrales nos servirán como caso de estudio.

La evolución de la autonomía del Banco de España es conocida, por lo que bastará con recordar que en una primera fase se le dotó de un régimen de independencia administrativa y gubernamental (Ley 13/1994) que planteaba dificultades de encaje constitucional, dado que la CE atribuye al Gobierno la dirección política y administrativa y en torno a aquel articula el sistema de control parlamentario (arts. 97 y 108 $\mathrm{CE})^{63}$. En todo caso, en aquella primera fase el Parlamento retenía el control último, en cuanto la autonomía había sido otorgada por una ley ordinaria susceptible de modificación o derogación. Sin embargo, en la actual fase la independencia es también parlamentaria, por aplicación del Derecho de la UE (art. 130 TFUE), e implica una reserva de administración frente al Parlamento ${ }^{64}$ (reglamentaria y ejecutiva) ${ }^{65}$ y la inamovilidad de los responsables de la institución ${ }^{66}$.

tal legitimación cuando corresponde al Parlamento el control de la acción del Gobierno y, para ello, se legitima a un número suficiente de parlamentarios para impugnar leyes ante la justicia constitucional.

63 Andrés BETANCOR, Las administraciones independientes, Tecnos, Madrid, 1994, pp. 143 y 154.

${ }^{64}$ GARCÍA-ANDRADE, 2000, pp. 192 y ss.; José María BAÑO LEÓN, "Reserva de Administración y Derecho comunitario", en Carlos ESPLUGUES et al. (coord.), Nuevas fronteras del derecho de la Unión Europea, Tirant lo Blanch, Valencia, 2012, pp. 837-850; y Xabier ARZOZ SANTISTEBAN, "La autonomía institucional y procedimental de los Estados miembros en la Unión Europea: mito y realidad”, Revista de Administración Pública, núm. 191, 2013, pp. 159-197 (p. 177).

65 STJUE de 3 de diciembre de 2009, C-424/07, Comisión v. Alemania, sobre la exclusión del Parlamento en el ámbito de decisión de la autoridad nacional independiente en materia de telecomunicaciones.

${ }^{66}$ STJUE de 19 de octubre de 2016, C-424/15, Ormaetxea et al., sobre la separación indebida de los vocales de una autoridad independiente; y STJUE de 26 de febrero de 2019, C202/18 y C238/18, 
El problema constitucional es material y no únicamente formal, ya que no se trata simplemente de que la independencia de las autoridades entre en colisión textual con la letra de determinados preceptos constitucionales, sino que, incluso si se modificase la Constitución para acoger expresamente este tipo de autoridades, el ordenamiento jurídico seguiría sin contar con una fórmula para integrarlas en el sistema de controles y de división de poderes (como acontece actualmente en los Tratados de la UE respecto del BCE). Hoy el núcleo del problema se sitúa en el uso asimétrico del principio de división de poderes, pues, por una parte, este se juzga insuficiente en su formulación tradicional, por lo que se ha profundizado en la división, extendiéndola al seno del propio Ejecutivo, del que se escinden importantes ámbitos de decisión mediante la creación de autoridades independientes. Sin embargo, por otra parte, se han mantenido las tradicionales técnicas de control de la división de poderes, sin que se haya articulado un modelo adaptado a la nueva realidad. Tampoco el control jurisdiccional se antoja suficiente para las exigencias de un Estado democrático y de Derecho $^{67}$, pues los tribunales solo pueden revisar las decisiones administrativas de manera rogada; además, su canon de enjuiciamiento es exclusivamente la legalidad, por lo que no existe control de oportunidad; y, finalmente, se enfrentan a materias altamente técnicas ${ }^{68}$, por lo que aquel control es muchas veces exclusivamente formal, dado que difícilmente resulta posible controlar el acierto de las decisiones macroeconómicas. Con el resultado de que, por el camino, parcelas completas del Ejecutivo han dejado de ser controladas por el Parlamento, lo que seguramente exija fórmulas nuevas de control mediante órganos especializados, como se apunta enseguida.

\subsubsection{El solapamiento de las nuevas autoridades}

La creación de nuevas autoridades macroeconómicas para atender nuevos cometidos no siempre está antecedida de un análisis de conjunto para integrarlas en el entramado institucional previamente existente. Por el contrario, más bien se advierte una respuesta de corte muy sectorial, con frecuencia diseñada en abstracto para muy distintos ordenamientos, pero sin adecuación a la particular configuración constitucional de cada Estado, al modelo de organización territorial, ni a la existencia de autoridades previas con las que con frecuencia se producen solapamientos.

Así, la AIReF vela por el cumplimiento de los principios de estabilidad presupuestaria y sostenibilidad financiera mediante la evaluación continua del ciclo presupuestario, del endeudamiento público, y también realiza tareas prospectivas como

Rimševičšs, por la que anula una medida nacional de suspensión en el cargo del gobernador de un banco central nacional.

${ }^{67}$ A pesar de que la jurisprudencia del TJUE parece hacer descansar en los tribunales el control de las nuevas autoridades independientes: STJUE de 9 de marzo de 2010, C-518/07, Comisión v. Alemania, apartado 42.

${ }_{68}$ El problema que plantea el control jurisdiccional de decisiones administrativas de contenido técnico ha sido objeto de un análisis renovado en Autonomía administrativa, decisiones cualificadas y deferencia judicial, Elisenda MALARET GARCÍA (dir.), Aranzadi, Cizur Menor, 2019. 
el análisis de las previsiones macroeconómicas (art. 2 de la Ley Orgánica 6/2013), pero en algunos de estos cometidos se solapa con la función asignada al Tribunal de Cuentas, como supremo órgano fiscalizador de las cuentas y de la gestión económica del Estado y del sector público (art. 1.1 LOTC). A pesar de que ambas instituciones incidan sobre parcelas comunes, resulta llamativo que la regulación de la AIReF solo mencione al Tribunal de Cuentas respecto de la fiscalización de la propia AIReF (art. 12.5), pero no establezca criterios de delimitación competencial o cooperación. $Y$ es que entre los retos de la incipiente regulación se encuentra la reconsideración de las viejas y nuevas autoridades económicas para adecuarlas a las nuevas necesidades surgidas.

\subsubsection{La necesidad de órganos consultivos y de control macroeconómico}

La creación o transformación de las autoridades macroeconómicas responde esencialmente a los intentos de reducir la discrecionalidad en las políticas públicas y a las lecciones aprendidas en la crisis de 2007. Sin embargo, falta una valoración de conjunto de las necesidades de asesoramiento y de control especializado que la irrupción de la política macroeconómica plantea al Estado, siendo así que la creación de este tipo de órganos podría contribuir a suplir las carencias señaladas a lo largo del trabajo: déficit de conocimiento y de control por parte del Parlamento y los tribunales; déficit de participación y de transparencia.

Desde el punto de vista consultivo, algunas de las autoridades económicas, como los bancos centrales, cuentan con potentes servicios de estudios económicos que les proporcionan la información, los análisis y el asesoramiento precisos para el ejercicio de sus funciones. Sin embargo, el Estado en su conjunto carece de órganos consultivos en materia macroeconómica, lo que dificulta el ejercicio de la función parlamentaria, gubernamental, la transparencia informativa y la participación ciudadana. $\mathrm{Al}$ igual que la especialidad e importancia del Derecho han exigido tradicionalmente que el Estado contara con órganos consultivos en aquella materia, la macroeconomía ha adquirido tal relevancia en la actualidad que el Estado y la sociedad contemporánea requieren un asesoramiento independiente en materia macroeconómica, que tanto de oficio como de forma rogada oriente sobre la situación macroeconómica, las previsiones de evolución, los efectos previsibles de las distintas medidas y de sus alternativas.

También resulta insuficiente el actual sistema de control de las decisiones macroeconómicas. En efecto, el contenido muy técnico de la macroeconomía impide un auténtico control por los tribunales, por lo que tal control se está encomendando en parte a autoridades especializadas, como la AIReF y la Autoridad Macroprudencial Consejo de Estabilidad Financiera. Sin embargo, este control institucional no debería proyectarse únicamente respecto de las decisiones adoptadas por las viejas autoridades económicas, sino también respecto de algunas de las de nuevo cuño, como las autoridades independientes. Ahora bien, en la actualidad la idea de introducir 
cualquier control sobre las autoridades independientes se ha convertido en una suerte de tabú. Repárese, si no, en la regulación de las autoridades macroprudenciales en el ámbito financiero. Estas surgieron tras la crisis económica de 2007, ante la evidencia de que en la economía pueden larvarse desequilibrios sistémicos ${ }^{69}$ (como las burbujas inmobiliarias o bursátiles), que no sean detectados por las autoridades económicas tradicionales e incluso sean alimentados involuntariamente por ellas y que terminen por provocar graves crisis financieras. Para detectar tales desequilibrios y minimizarlos se han creado autoridades como la Junta Europea de Riesgo Sistémico y su homóloga nacional la Autoridad Macroprudencial Consejo de Estabilidad Financiera. Su concepción es ciertamente innovadora, pues extienden su control sobre casi todo el conjunto de la economía, incluidas otras autoridades públicas que ejercen sus competencias en régimen de autonomía ${ }^{70}$. Y precisamente para conjugar el necesario control que desarrollan con la preservación de la autonomía de las autoridades controladas se han diseñado nuevos instrumentos jurídicos, como advertencias y recomendaciones, que pueden llegar a ser públicas para dotarlas de mayor efectividad ${ }^{71}$. Sin embargo, esta regulación ha dejado fuera de su control a los bancos centrales ${ }^{72}$, a pesar de que sus decisiones monetarias en los años previos a la crisis de 2007 contribuyeron involuntariamente a la formación de los desequilibrios que la desencadenaron ${ }^{73}$. En otras palabras, se requiere articular jurídicamente sistemas de control respecto de las decisiones macroeconómicas, ya sean estas adoptadas por las viejas autoridades o por las de nuevo cuño, sin que el régimen de autonomía de estas últimas deba constituir un obstáculo, pues, como acaba de exponerse, el ordenamiento jurídico ha desarrollado un prontuario de técnicas que permiten conciliar el control con la preservación de la autonomía. Para desarrollar este control se antoja imprescindible contar con órganos independientes y especializados en materia macroeconómica.

${ }^{69}$ M. Amparo SALVADOR ARMENDÁRIZ, "El riesgo sistémico en la regulación bancaria: una aproximación a las respuestas del derecho a la crisis financiera", Revista Jurídica de Navarra, núm. 50, 2010, pp. 145-170 (p. 149).

70 Art. 16.2 y apartado 14 del preámbulo del Reglamento 1092/2010, del Parlamento Europeo y del Consejo, de 24 de noviembre de 2010, relativo a la Supervisión Macroprudencial del Sistema Financiero en la Unión Europea y por el que se Crea una Junta Europea de Riesgo Sistémico.

71 Art. 16 y apartado 21 del preámbulo del Reglamento 1092/2010.

72 En el Derecho español, la autoridad macroprudencial incluso está dirigida por los responsables de las autoridades sobre las que debería proyectar su control (art. 7 del Real Decreto 102/2019).

73 El Informe de Jacques DE LAROSIËRE, The high-level group on financial supervision in the EU. Report, apartados 6 y 43, elaborado a petición de la UE, destaca que la política de bajos tipos de interés y abundante liquidez fue determinante en el desencadenamiento de la crisis. Este Informe describe la causa, pero no identifica al sujeto responsable de ella y de esta manera evita mencionar de manera directa la responsabilidad de los bancos centrales. También el Banco de Pagos Internacionales ha señalado la política monetaria como una de las dos causas macroeconómicas de la crisis, Bank for International Settlements, 78th Annual Report, 1 April 2007-31 March 2008, pp. 7-8, y 79th Annual Report, 1 April 2008-31 March 2009, pp. 5-6 y 16. Asimismo, el Memorando para el rescate de la economía española de 2012, reconocía explícitamente en su apartado 2 que "Los bajos tipos de interés reales desencadenaron la acumulación de grandes desequilibrios internos y externos, así como la creación de una burbuja inmobiliaria". En fin, otro tanto hace el antiguo Gobernador del Banco de España Miguel Ángel FERNÁNDEZ ORDÓNEZZ, "Las tribulaciones de los bancos centrales", El País, 2 de octubre de 2019. 
A modo de conclusión general, cabe reparar en que, desde su surgimiento, la macroeconomía viene planteando importantes retos al Derecho público. En un primer estadio, desde el Derecho público no se supo ver el enorme poder que las autoridades públicas habían adquirido en materia macroeconómica y, cuando se cobró plena conciencia de esta circunstancia, una miríada de regulaciones ha buscado únicamente la reducción de la discrecionalidad macroeconómica de las autoridades. Pero el reto del Derecho público es ir más allá del control de la discrecionalidad macroeconómica y adecuar sus técnicas e instituciones a un fenómeno que ha transformado la operativa de los Estados contemporáneos y que condiciona de manera muchas veces difusa pero muy incisiva la vida de los ciudadanos, de tal manera que se preserven los principios irrenunciables y trabajosamente conquistados en el Estado democrático de Derecho.

\section{BIBLIOGRAFÍA}

ARIÑO ORTIZ, Gaspar, Principios de Derecho público económico, Comares, Granada, 2004.

ARZOZ SANTISTEBAN, Xabier, "La autonomía institucional y procedimental de los Estados miembros en la Unión Europea: mito y realidad”, Revista de Administración Pública, núm. 191, 2013, pp. 159-197.

ASOCIACIÓN DE LETRADOS DEL TRIBUNAL CONSTITUCIONAL, Crisis y Constitución, CEPC, 2015.

BACIGALUPO, Mariano, La discrecionalidad administrativa, Marcial Pons, Madrid, 1997.

BALLBÉ, Manuel y PADRÓS I REIG, Carlos, Estado competitivo y armonización europea: los modelos norteamericano y europeo de integración, Ariel, Barcelona, 1997.

BAÑO LEÓN, José María, "Reserva de Administración y Derecho comunitario", en Carlos ESPLUGUES et al. (coord.), Nuevas fronteras del derecho de la Unión Europea, Tirant lo Blanch, Valencia, 2012, pp. 837-850.

BASSOLS COMA, Martín, "La reforma del articulo 135 de al Constitución espańola y la constitucionalización de la estabilidad presupuestaria: el proceso parlamentario de elaboración de la reforma constitucional", Revista Española de Derecho Administrativo, núm. 2-155, 2012, pp. 21-41.

BECK, Thorsten, y KOTZ, Hans-Helmut (eds.), Ordoliberalism: A German oddity?, CEPR Press, 2017.

BETANCOR, Andrés, Las administraciones independientes, Tecnos, Madrid, 1994.

BLANCHARD, Olivier, Macroeconomia, 7. a ed., Pearson, Madrid, 2017.

BLASCO ESTEVE, Avelino (coord.), El Derecho público de la crisis económica. Transparencia y sector público. Hacia un nuevo Derecho administrativo. Actas del VI Congreso de la Asociación Española de Profesores de Derecho Administrativo, INAP, Madrid 2012.

BRUNNERMEIER, Markus K. et al., The Euro and the Battle of Ideas, Princeton University Press, Princeton, 2016.

BUCHANAN, James, y WAGNER, Richard E., Democracy in Deficit, Academic Press, New York, 1977.

CARANDE, Ramón, Carlos Vy sus banqueros, Crítica, Barcelona, 2000.

CARRASCO DURÁN, Manuel, "Estabilidad presupuestaria y Comunidades Autónomas", Revista d'Estudis Autonòmics i Federals, 18, 2013, pp. 169-206.

COSCUlLUELA MONTANER, Luis (dir.), Estudios de Derecho Público Económico. Libro Homenaje al Prof. Dr. D. Sebastián Martín-Retortillo, Civitas, Madrid 2003.

Crónica Presupuestaria, núm. 1, 2013.

COSCULLUELA MONTANER, Luis, y LÓPEZ BENÍTEZ, Mariano, Derecho público económico, Iustel, Madrid, 2011. 
DARNACULLETA I GARDELLA, M. Mercè, "Conseqüències institucionals de la limitació del deute públic a les comunitats autònomes i als Länder. Una anàlisi comparada dels mecanismes de control de l'estabilitat pressupostària a Espanya i Alemanya", Revista d'Estudis Autonòmics i Federals, núm. 20, 2014, pp. 174-213.

DE LA QUADRA-SALCEDO, Tomás, “Techo de gasto y separación de poderes”, El País, 27 de agosto de 2018.

DELGADO RAMOS, David, "La reciente constitucionalización de la estabilidad presupuestaria: ¿̨una reforma necesaria?", Revista de Derecho Politico, 87, 2013, pp. 317-352.

DE MIGUEL BÁRCENA, Josu, "Estabilidad financiera en entornos federales: la nueva Constitución económica del riesgo", Revista de Derecho Constitucional Europeo, núm. 26, julio-diciembre, 2016.

DOMÉNECH PASCUAL, Gabriel, "Por qué y cómo hacer análisis económico del derecho", Revista de Administración Pública, núm. 195, 2014, pp. 99-133.

EKELUND, Robert B., y HÉBERT, Robert F., Historia de la teoría económica y de su método, 3. ${ }^{\mathrm{a}}$ ed., McGraw-Hill, Madrid, 1991.

EMBID IRUJO, Antonio, La constitucionalización de la crisis económica, Iustel, Madrid, 2012.

ESTEVE PARDO, José, El pensamiento antiparlamentario y la formación del Derecho público en Europa, Marcial Pons, Madrid, 2019.

FERNÁNDEZ ORDÓNEEZ, Miguel Ángel, "Las tribulaciones de los bancos centrales”, El País, 2 de octubre de 2019.

FLEINER, Fritz, Instituciones de Derecho Administrativo, Labor, Barcelona, 1933.

GALBRAITH, John Kenneth, Historia de la economia, 3.a ed., Ariel, Barcelona, 1989.

GARCÍA ALCORTA, José, El Banco Central Europeo, Civitas, Madrid, 2011.

GARCÍA ROCA, Javier, y MARTÍNEZ LAGO, Miguel Ángel, Estabilidad presupuestaria y consagración del freno constitucional al endeudamiento, Civitas, Madrid, 2013.

GARCÍA-ANDRADE GÓMEZ, Jorge, "El sistema monetario en una Unión Europea de Derecho", en SALVADOR ARMENDÁRIZ, M. Amparo (dir.), Regulación bancaria: transformaciones y Estado de Derecho, Aranzadi, Cizur-Menor, 2014, pp. 251-320.

— "La adopción de la estabilidad presupuestaria en la Constitución Española", Ius Publicum Network Review, 2013, núm. 3, pp. 1-69.

- "La aplicación del principio constitucional de estabilidad presupuestaria a las entidades locales", en COSCULLUELA MONTANER, Luis, y MEDINA ALCOZ, Luis (dirs.), Crisis económica y reforma del régimen local, Civitas, Madrid, 2012, pp. 293-325.

- La posición jurídica del Banco de España en el Sistema Europeo de Bancos Centrales, Civitas, Madrid, 2000.

— "La reforma del artículo 135 de la Constitución Española", Revista de Administración Pública, núm. 187, 2012, pp. 31-66.

— "Regulación de precios aeroportuarios: reserva de ley y liberalización económica", en A. RUIZ OJEDA y R. ZAMORA (eds.), Regulación y competencia en servicios de interés económico general (SIEG): análisis sectoriales y comparativos, Universidad de Málaga, Málaga, 2015, pp. 131-162.

GONZÁLEZ GARCÍA, Julio V., "Globalización económica, Administraciones públicas y Derecho administrativo: presupuestos de una relación”, Revista de Administración Pública, núm. 164, 2004, pp. 7-40.

JUDT, Tony, Ill fares the land, Penguin, Nueva York, 2010.

KYDLAND, Finn E., y PRESCOTT, Edward C., "Rules Rather than Discretion: The Inconsistency of Optimal Plans", Journal of Political Economy, vol. 85, 1977, pp. 473-491.

LAGUNA DE PAZ, José Carlos, Derecho administrativo económico, Civitas, Madrid, 2019.

MALARET GARCÍA, Elisenda (dir.), Autonomía administrativa, decisiones cualificadas y deferencia judicial, Aranzadi, Cizur-Menor, 2019.

MANZANEDO MATEOS, José Antonio et al., Curso de Derecho administrativo económico, Instituto de Estudios de Administración Local, Madrid, 1970.

MARTÍ DEL MORAL, Antonio, "La constitucionalización del principio de estabilidad presupuestaria”, en COSCULLUELA MONTANER, Luis, y MEDINA ALCOZ, Luis (dirs.), Crisis económica y reforma del régimen local, Civitas, Madrid, 2012, pp. 271-292 
MARTÍN MATEO, Ramón, y SOSA WAGNER, Francisco, Derecho administrativo económico, Pirámide, Madrid, 1977.

MARTÍN-ACENAA, Pablo, “The Banco de España, 1782-2017. The history of a central bank", Estudios de Historia Económica, núm. 73, 2017, pp. 1-80.

MARTÍN-RETORTILLO BAQUER, Sebastián, Derecho Administrativo económico, La Ley, Madrid, vol. I, 1988.

— "Las nuevas perspectivas de la Administración económica", Revista de Administración Pública, núm. 116, 1988, pp. 31-47.

MONTERO PASCUAL, Juan José, Regulación económica, Tirant lo Blanch, Valencia, 2018.

MORENO GONZÁLEZ, Gabriel, "La teoría de la Constitución en James Buchanan: hacia un modelo de economía constitucional", Revista de Estudios Politicos, núm. 177, 2017, 1-36.

NEUMARK, Fritz, Principios de la imposición, Instituto de Estudios Fiscales, Madrid, 1994.

ORRIOLS I SALLÉS, M. Àngels, El Banco Central Europeo y el sistema europeo de bancos centrales. Régimen jurídico de la autoridad monetaria de la Comunidad Europea, Comares, Granada, 2004.

ORRIOLS SALLÉS, M. Àngels, y ROCA SAGARRA, Joan, El Banco de España y estructura plural: los modelos administrativos de la Reserva Federal americana y del Bundesbank alemán, Marcial Pons, Madrid, 1997.

PIÑAR MAÑAS, José Luis (coord.), Crisis económica y crisis del Estado de Bienestar. El papel del Derecho administrativo. XIX Congreso Italo Español de Profesores de Derecho Administrativo, Reus, Madrid, 2013.

PRADO PRADO, Gabriela, La autoridad monetaria en el sistema institucional de la Unión Europea, Tecnos, Madrid, 2006.

REQUEJO RODRÍGUEZ, Paloma, "El papel de la crisis económica en la argumentación del Tribunal Constitucional. Comentario a la STC 19/2014", Teoría y Realidad Constitucional, núm. 36, 2015, pp. 417-437.

Revista Vasca de Administración Pública, 110-II, 2018.

RIVERO ORTEGA, Ricardo, Derecho administrativo económico, Marcial Pons, Madrid, 2018.

RODRÍGUEZ BEREIJO, Álvaro, "La reforma constitucional del artículo 135 CE y la crisis financiera del Estado", Crónica Presupuestaria, 1, 2013, pp. 5-39.

RODRÍGUEZ ZAPATERO, José Luis, El dilema, Planeta, Barcelona, 2013.

RUIZ ALMENDRAL, Violeta, "Estabilidad Presupuestaria y Reforma Constitucional", Revista Española de Derecho Europeo, núm. 41, 2012, pp. 33-112.

RUIZ OJEDA, Alberto (dir.), Fundamentos de regulación y competencia: (el diálogo entre derecho y economía para el análisis de las politicas públicas), Iustel, Madrid, 2013.

SAINZ DE BUJANDA, Fernando, "Estado de derecho y Hacienda pública", Revista de Administración Pública, núm. 6, 1951, pp. 193-212.

SALVADOR ARMENDÁRIZ, M. Amparo, "El principio constitucional de estabilidad presupuestaria y el derecho administrativo", XIV STEM, 2019, pp. 1-49.

- "El riesgo sistémico en la regulación bancaria: una aproximación a las respuestas del derecho a la crisis financiera”, Revista Jurídica de Navarra, núm. 50, 2010, pp. 145-170

SANTACREU SOLER, José Miguel, "La revolución monetaria española de 1968", Anales de Historia Contemporánea, núm. 10, 1994, pp. 511-523.

SARDÁ, Joan, La política monetaria y las fluctuaciones de la economía española en el siglo XIX, Alta Fulla, Barcelona, 1998.

SCHMIDT-ASSMANN, Eberhard, "Cuestiones fundamentales sobre la reforma de la teoría general del Derecho administrativo", en Javier BARNES (ed.), Innovación y reforma en el Derecho adminis-

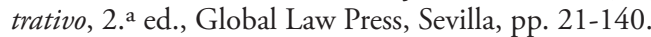

SIMÓES PATRÍCIO, José, "Autonomía de los bancos centrales: perspectiva de Derecho comparado", Revista de Derecho Bancario y Bursátil, núm. 69, 1998, pp. 9-44.

SKIDELSKY, Robert, John Maynard Keynes, RBA, Barcelona, 2013.

STOLLEIS, Michael, Origins of the German Welfare State, Marcial Pons, Springer, Berlin, 2013.

Teoría y Realidad Constitucional, núm. 29, 2012. 
TOMÁS Y VALIENTE, Francisco, Obras completas. Manual de Historia del Derecho español, vol. II, Centro de Estudios Políticos y Constitucionales, Madrid, 1997.

TUORI, Klaus, “¿Órgano experto, institución política o parte interesada? Roles del banco central europeo en la actual crisis económica”, El Cronista del Estado social y democrático de Derecho, núm. 39, 2013, pp. 50-61.

VICENS VIVES, Jaume, Historia económica de España, Ed. Vicens Vives, 1974. 